\title{
Teams as Complex Adaptive Systems: Reviewing 17 Years of Research
}

\author{
Pedro J. Ramos-Villagrasa', \\ Pedro Marques-Quinteiro², \\ José Navarro ${ }^{3}$, and Ramón Rico ${ }^{4}$
}

\begin{abstract}
At the turn of the century, Arrow, McGrath, and Berdahl portrayed teams as complex adaptive systems (CAS). And yet, despite broad agreement that this approach facilitates a better understanding of teams, it has only now been timidly incorporated into team research. To help fully incorporate the logic of teams as CAS in the science of teams, we review extant research on teams approached from a nonlinear dynamical system theory. Using a systematic review approach, we selected 92 articles published over the last 17 years to integrate what we know about teams as CAS. Our review reveals the evidence supporting teams as CAS, and the set of analytical techniques to analyze team data from this perspective. This review contributes to teams' theory and practice by offering ways to identify both research methods and managing techniques that scholars and practitioners may apply to study and manage teams as CAS.
\end{abstract}

\footnotetext{
'Universidad de Zaragoza, Spain

2ISPA — Instituto Universitário, Lisbon, Portugal

${ }^{3}$ Universidad de Barcelona, Spain

${ }^{4}$ The University of Western Australia, Perth, Australia
}

\section{Corresponding Author:}

Pedro J. Ramos-Villagrasa, Facultad de Ciencias Sociales y del Trabajo, Universidad de Zaragoza, despacho 35. Calle Violante de Hungría, 23, 50009 Zaragoza, Spain.

Email: pjramos@unizar.es 


\section{Keywords}

teams, complex adaptive systems, nonlinear dynamical systems, systematic literature review

The time for team research is more propitious than ever, and the science of teams is going through one of its most exciting moments (e.g., Kozlowski, Chao, Chang, \& Fernandez, 2016; Mathieu, Tannenbaum, Donsbach, \& Alliger, 2014; Rico, Alcover, \& Tabernero, 2011). However, developments in this field have revealed several unresolved issues; one issue is the consideration of teams as complex adaptive systems (CAS; Arrow, McGrath, \& Berdahl, 2000). The seminal work of Arrow et al. has been well received and widely cited (e.g., Google Scholar: 865 citations $^{1}$ ). Nevertheless, a paradoxical situation exists. On one hand, it is easy to find a conceptualization of teams as CAS (or at least a conceptualization of teams acknowledging their complexity); on the other hand, the number of empirical research endeavors that really incorporate this conceptualization of teams remains scarce.

CAS have been proposed as a core construct of nonlinear dynamical systems (NDS) theory (Lewin, 1993). They involve a set of independent agents acting in parallel to develop models of how things function in their setting, and to refine such models through learning and adaptation (Gell-Mann, 1994). Accordingly, CAS are open systems characterized by uncertainty about their evolution over time, due to the interaction of their components (Guastello \& Liebovitch, 2009). The popularization of CAS is due to the progressive evidence that many natural and social phenomena (from ant farms to social organizations) exhibit chaotic behavior. So, it was a matter of time until the CAS concept was applied to organizational science, and to team research afterward (Dooley, 1997; Guastello, 2009). Following this approach, teams are characterized as (a) complex, because they are entities embedded in organizations showing complex behavior; (b) adaptive, because they behave dynamically in dealing with environmental changes; and (c) systems, due to their functioning being dependent both on the team's history and on its anticipated future (Arrow et al., 2000).

Thus, thinking of teams as CAS is more than a metaphor to explain teams functioning, and it is more than a set of nonlinear tools to analyze team behavior. It leads to a change in the epistemology of teams which, in turn, gives team researchers the opportunity to (a) adopt a different logic of inquiry, (b) to deal with temporal issues, (c) to raise the level of theoretical sophistication, and (d) thus to lead to better practical applications (McGrath, Arrow, \& Berdahl, 2000; Navarro, Roe, \& Artiles, 2015). The use of NDS to study CAS emphasizes the study of team functioning rules and reveals what bends these 
rules. In that sense, CAS do not complicate the science of teams, but simplify it, making it more natural, and closer to how phenomena happen (Anderson, Meyer, Eisenhardt, Carley, \& Pettigrew, 1999; McGrath et al., 2000).

Despite these advantages and the existing empirical evidence, mainstream research is predominantly plagued by linear ${ }^{2}$ thinking and chain-like causeeffect connections between pools of variables (Navarro et al., 2015). We suspect this gap may be due to the difficulties researchers find in adopting the NDS approach, which is probably aggravated by the way NDS researchers disseminate their work. To redress this gap, we systematically reviewed the state of the art on teams as CAS. To do so, we first systematized current knowledge about empirical research on teams as CAS; then, we showed the added value of using the NDS theory on team research and, finally, we outlined several guidelines regarding which conceptual, methodological, and practical approaches may be implemented by scholars and practitioners to study and manage teams as CAS.

\section{Systematizing Current Knowledge: A Review of Teams as CAS}

For the scope of this review, and to minimize the bias associated with the traditional heuristic approach, we adopted a replicable, objective, and transparent process of systematic review (Tranfield, Denyer, \& Smart, 2003). Thus, we first elaborated on the search criteria selection and the review process itself, to then extract several empirical results from the review and elaborate on them.

\section{Article Search and Selection}

Following previous recommendations on systematic literature reviews (e.g., Cook, Mulrow, \& Haynes, 1997), we adopted a three-step approach to select the manuscripts for review. We started by agreeing on the search criteria, and restricted our search to two online databases: EBSCOhost (using PsycINFO, PsyARTICLES, Academic Search Complete, Business Source Complete, and Education Resources Information Center [ERIC] databases) and Web of Science (using Business Economics, Psychology, Computer Science, Sport Science, Social Sciences Other topics, and Behavioral Sciences domains). To generate the search criteria, we paired the word "team"3 with the following keywords: dynamics, non-linear dynamics, chaos, chaotic, complex adaptive systems, fuzzy sets, ${ }^{4}$ phase space, phase transition, perturbation, stability, and social network analysis. We searched for peer-reviewed empirical papers using quantitative methods for hypotheses testing published between 2000 
and 2016 (qualitative research and case studies were not considered). Finally, we received six papers from requests to the (a) Academy of Management Organizational Behavior mailing list for unpublished studies, (b) the newsletter of the Society for Chaos Theory in Psychology and Life Sciences and its associated distribution list, and (c) EAWOP Small Group Meeting on nonlinear dynamics in work and organizational psychology participants (Barcelona, Spain, October 2016).

We continued our selection process by submitting the manuscripts to three consecutive filtering rounds. In the first round, we found 2,516 articles. These were screened in the second round to determine which papers would be further reviewed, and to remove duplications. This involved applying two sets of exclusion criteria (Tranfield et al., 2003). First, before abstract screening, we identified whether the articles were (a) noncompliant with the established selection criteria, (b) focused on individual or organizational-level phenomena, (c) using nonhuman samples (e.g., computational simulations, virtual agents; robots), and (d) exclusively applying linear analytical techniques to analyze data. Second, during abstract screening, we looked for (e) search words that were acronyms for unrelated topics (e.g., Congenital High Airway Obstruction Syndrome; CHAOS) and (f) keywords with a different meaning from the one established by NDS theories (e.g., chaos meaning something complicated, rather than a system sensitive to initial conditions). As a result of applying the above criteria, we discarded $87 \%$ of the first round articles, keeping 326 articles to be reviewed again in the third round (see Figure 1). In the third round, complete papers were screened using the same exclusion criteria that had been applied in the second round. This resulted in 92 manuscripts to be systematically reviewed $(3.7 \%$ of those selected in the first round).

\section{Systematic Review Results}

We used eight indicators in our analysis to draw a full picture of the evolution of research on teams as CAS from 2000: (a) authorship, (b) institution, (c) country, (d) journal, (e) year of publication, (f) keywords, (g) research context and design, and (h) data analysis techniques. The quantification of indicators such as authorship, institution, or country will allow other researchers to identify top contributors in the field and reach out to engage in collaboration. Furthermore, it also informs about which nonacademic organizations have an interest in the topic, facilitating potential funding and data collection opportunities. Learning about the publication rate per year informs about evolution in the field. In addition, considering journals is important because they reveal how valuable a certain topic is, and help researchers decide where 


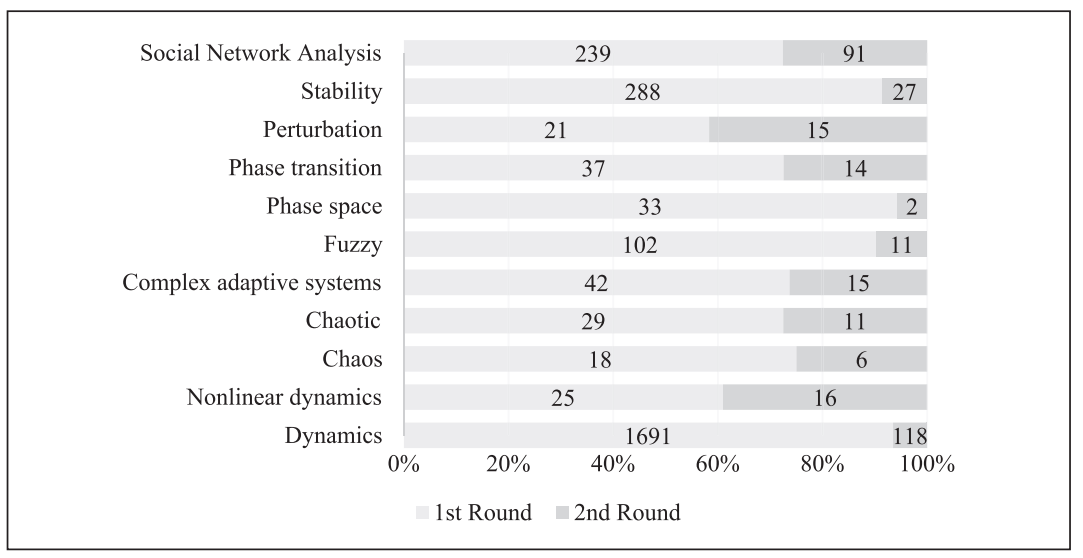

Figure I. Results for the frequency of articles (\%) found per keyword in the first and second rounds.

to submit a manuscript or where to look for studies. The quantification of keywords and research variables is a way of knowing which variables have been more studied. Quantifying research methods and designs, and data analysis techniques help in guiding future research regarding which settings (e.g., lab vs. field; sample size) and data analysis techniques (e.g., cusp catastrophe modeling; nonlinear time series analysis) are considered when teams are studied as CAS. Considering the above justifications, we next present our findings:

Authorship. According to Lotka's law (1926), a small number of authors publish most of the papers, with Keith Davis $(n=8)$ and Stephen J. Guastello $(n=10)$ having the highest number of contributions (13.86\%) on teams as CAS.

Institutions. Many institutions (81.13\%) are attributed with only one publication; the remaining $18.87 \%$ institutions were attributed with between two and 15 articles. The University of Lisbon $(n=15)$ is the institution with more articles published over 17 years.

Countries. Twenty-five countries were identified, with an average number of published articles per year being $M=5.15(S D=8.14)$. Thirty-six percent of the countries had only one publication, and $64 \%$ published between two and 41 articles over 16 years. The bar graph presented in Figure 2 shows that the United States $(n=41)$, Portugal $(n=17)$, and Spain $(n=8)$ were the countries presenting the highest number of publications over 17 years. 


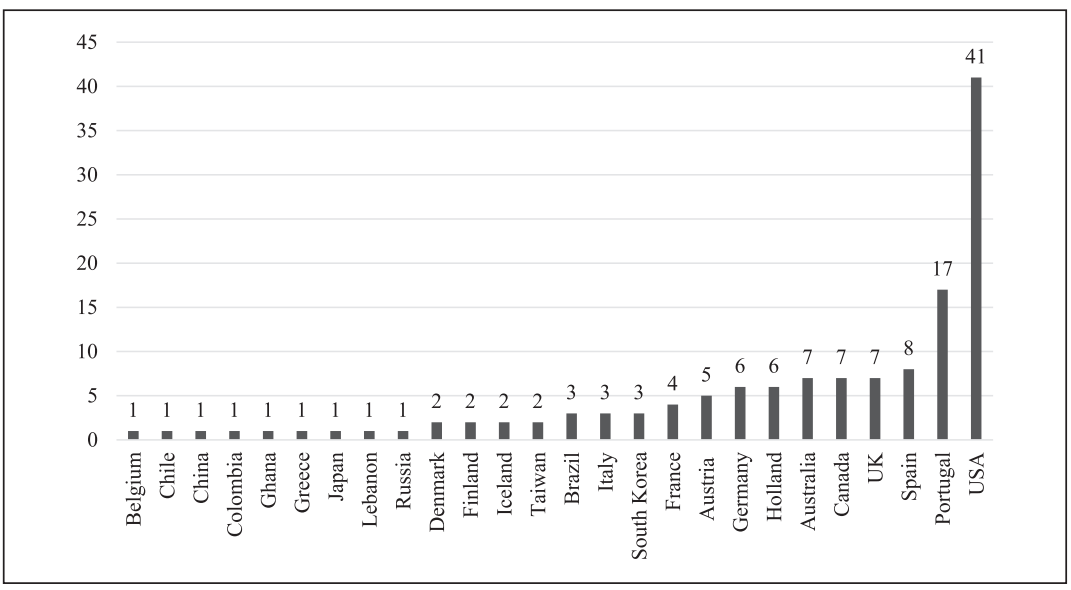

Figure 2. Results for the frequency of articles (\%) published between 2000 and 2016 per country.

Journals. Table 1 classifies the articles selected per journal impact factor and quartile through 2015 (inclusive) according to the Social Science Citation Index from the Journal Citation Reports. Despite the relatively low number of articles published over the 17 years, $60.2 \%$ of the selected articles were published in Quartile 1 and Quartile 2 journals. Considering the distribution of articles across scientific disciplines, research on teams as CAS has been mainly published in psychology (32.88\%), followed by sport science $(23.29 \%)$ and human factors $(13.7 \%)$ journals, while the remaining of the manuscripts were published under a wide set of disciplines, such as medicine (6.85\%), education $(4.11 \%)$, or statistics $(4.11 \%)$.

Publication year. On average, there were $M=5.31(S D=5.30)$ publications per year on teams as CAS during the analyzed period. The frequency of publications ranged from $0(2000,2001)$ to $14(2013)$, with $66 \%$ of publications occurring from 2012 onward. Figure 3 portrays the evolution of published manuscripts on teams as CAS.

Keywords. We found 287 keywords in the articles reviewed, such diversity led us to create 12 aggregation categories: (a) adaptation, (b) coordination, (c) decision making, (d) emergence and dynamics, (e) leadership, (f) methods and data analysis, (g) miscellaneous (for those lacking more than three research papers on that topic, and not fitting any other category), (h) NDS, (i) 
Table I. Indicator of Quality of Research on Teams Using NDS.

\begin{tabular}{lc}
\hline Quartile in JCR & $n(\%)$ \\
\hline Ist & $25(26.9)$ \\
2nd & $31(33.3)$ \\
3rd & $14(15.1)$ \\
4rd & $7(7.5)$ \\
Not in JCR & $10(10.8)$ \\
Unpublished & $6(6.5)$ \\
All & $93(100.0)$ \\
\hline
\end{tabular}

Note. The info belongs to the year in which the article was published excepting 2016. If the journal was indexed in Science Citation Index Expanded (SCIE) and Social Science Citation Index (SSCl), we used SSCI. NDS = nonlinear dynamical systems; JCR = journal citation reports.

social networks, (j) neuro- and psychophysiology, (k) performance, and (l) team context. Table 2 presents keyword numbers and examples per category. Excluding the miscellaneous category $(n=92)$, the most frequent keywords were related to methodological issues (methods and data analysis, $n=46$; NDS, $n=35$; and team context, $n=26$ ).

Research variables. We considered both independent and dependent variables $(N=205)$, and categorized them to simplify the description of our findings. The variables did not match our previous keyword categories, so we created new categories (e.g., movement) and skipped others (e.g., team context). Table 2 shows the number and examples of research variables per category. Excepting the miscellaneous category, the most frequent independent variables are concerned with coordination $(n=18)$, team composition $(n=16)$, and processes and emergent states $(n=15)$. With regard to dependent variables, the most frequent concerned coordination $(n=25)$ and team effectiveness $(n=14)$.

Research context and design. Forty-eight articles (51.06\%) comprised field data, whereas 35 articles (39.36\%) comprised lab data. From the manuscripts reporting lab data, 26 were experiments, and the remaining nine were computational simulations with human participants. Regarding sample characteristics, $70 \%$ of the participants in the studies reviewed were professional workers $(n=28)$ or athletes $(n=23)$. Thirty-six $(38.29 \%)$ articles reported having used a sample size of $\leq 10$ teams, $18(19.15 \%)$ articles reported having used a sample size of 11 to 30 teams, and $26(30.85 \%)$ articles reported having a sample 


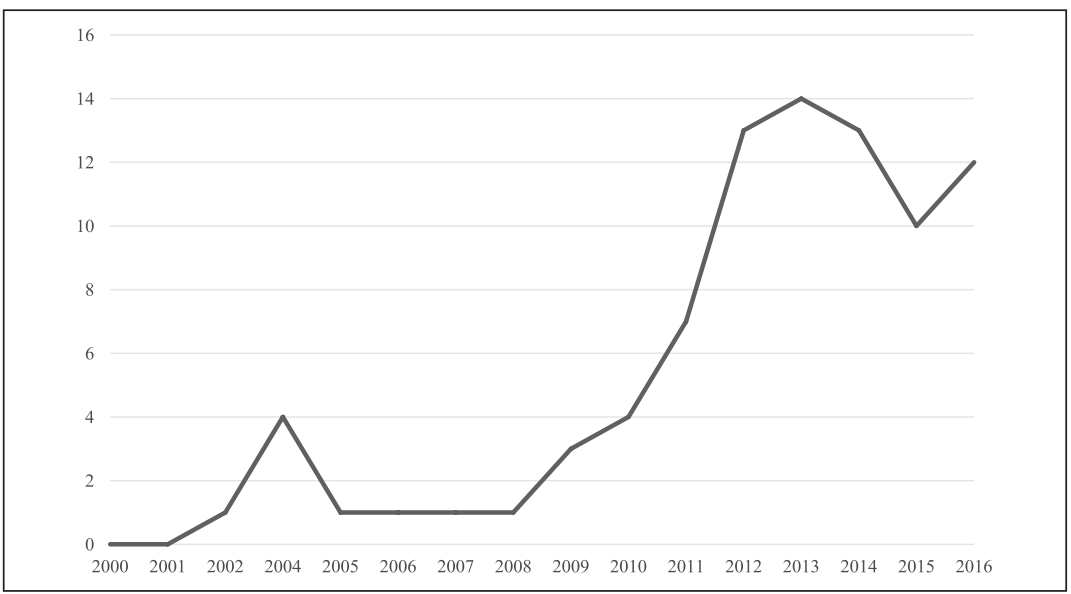

Figure 3. Results for the frequency of articles published between 2000 and 2016.

size of 31 or more teams. Finally, we found that many of the articles reviewed used more than one approach to data collection, often combining them. Figure 4 shows that self-reported data $(n=39)$ and objective data $(n=35)$ are the two most common data collection approaches, followed by human-rated interaction $(n=20)$ and the utilization of archival data $(n=14)$.

Data analysis techniques. We found 50 different data analytical techniques; these were categorized for the sake of parsimony. Table 3 shows that social network analysis $(n=37)$, time series $(n=22)$, ANOVA $(n=20)$, Pearson correlation $(n=16)$, and linear regression $(n=10)$ were commonly adopted by researchers for hypothesis testing. Regarding the NDS approach, entropy measures $(n=9)$ and maximum Lyapunov exponent $(n=5)$ are more frequent than the others.

Up to this point, we have shown the extent to which scholars and practitioners devoted attention to teams as CAS. Next, we presented how that attention added value to what we know about how teams work.

\section{Lessons Learnt From 17 Years of Teams as CAS}

Arrow et al. (2000) argued that there are three levels of causal dynamics that systematically and nonlinearly shape team functioning: (a) local dynamics (i.e., the behavior, cognition, and effects of team members in interaction with their environment), (b) global dynamics (i.e., the process and emergent structures 


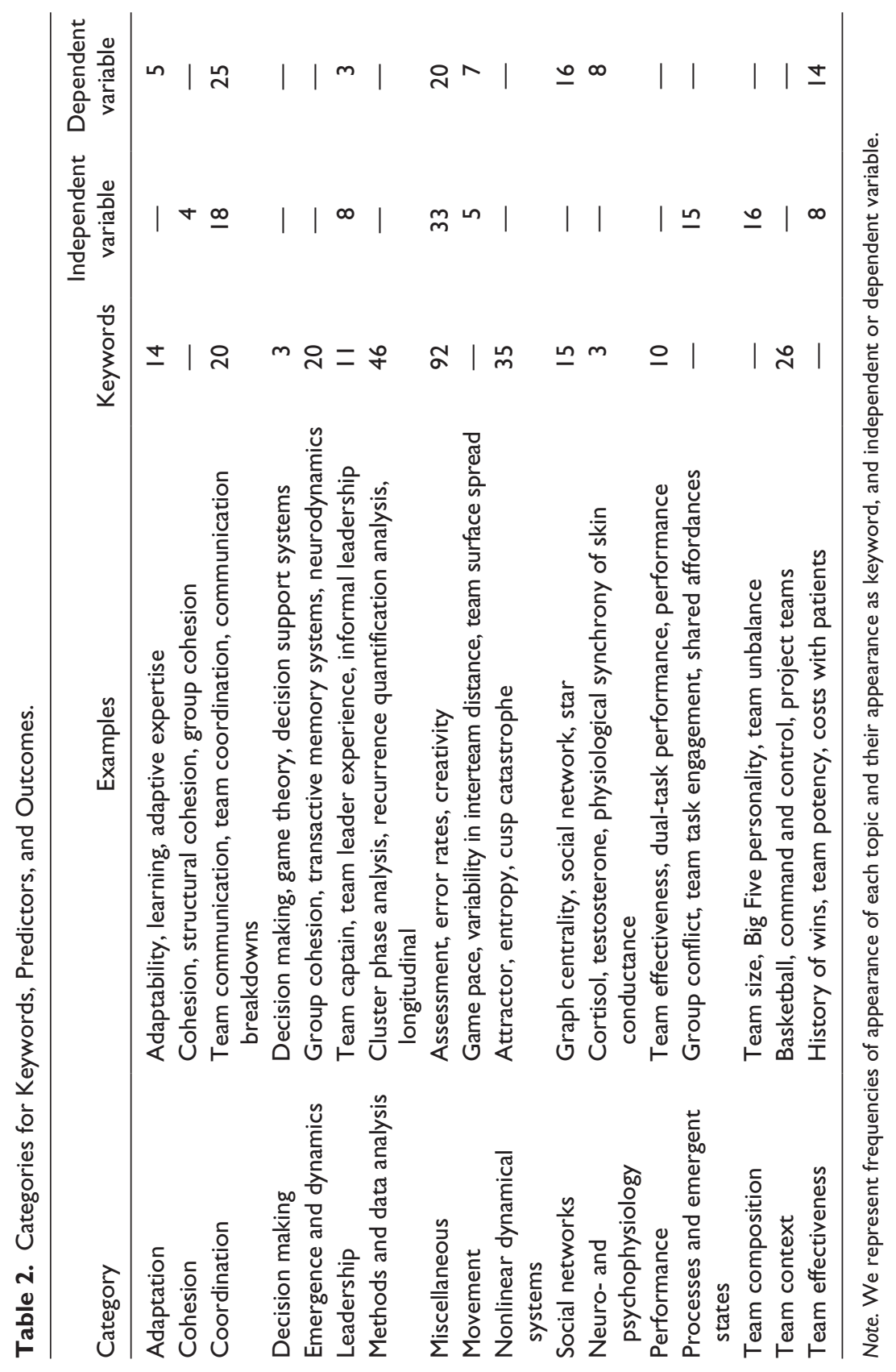




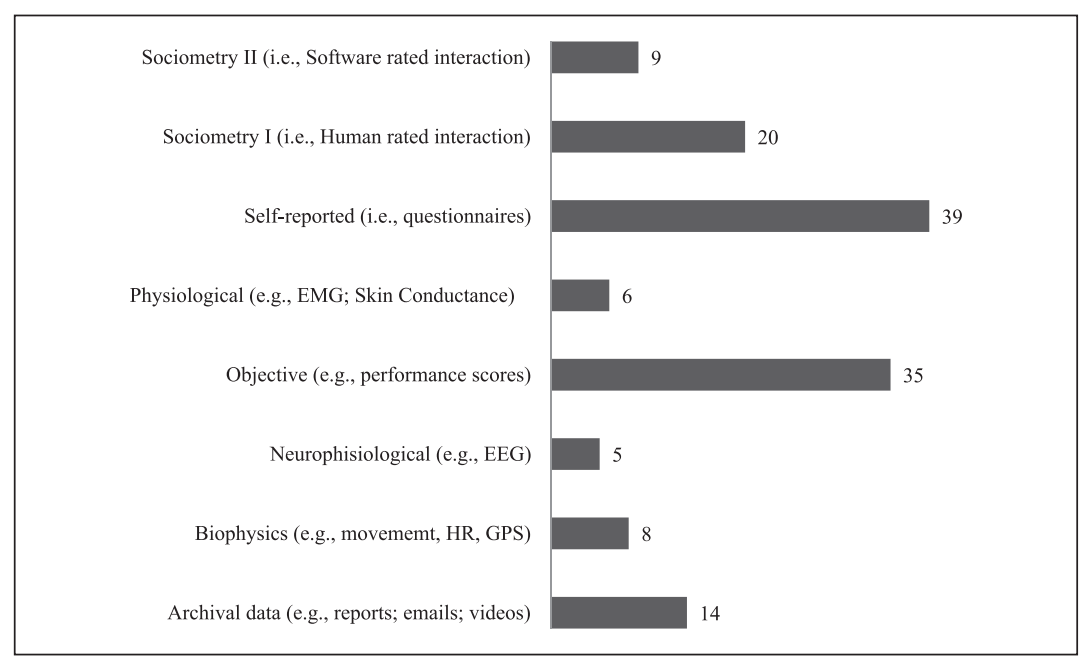

Figure 4. Results for the frequency of data collection approaches utilized in the articles (\%) published between 2000 and 2016.

that unfold as individuals and teams interact with their environment), and (c) contextual dynamics (i.e., the impact of context-specific features on teams' local and global dynamics). To systematize the lessons learned from our review, and connect them with the Arrow et al. (2000) taxonomy of causal dynamics in teams, we organized the reviewed papers in three clusters:

Cluster 1-local dynamics, including articles mostly about how team members develop central positions in their social network, and gain influence over team members and team outcomes (e.g., Klein, Lim, Saltz, \& Mayer, 2004);

Cluster 2-global dynamics, including manuscripts focusing on how group processes and emergent states emerge and unfold over time using combinations of linear (e.g., ANOVA) and nonlinear (e.g., nonlinear time series) methods (e.g., Sauer \& Kauffeld, 2015); and

Cluster 3-contextual dynamics, including articles revealing how team contextual factors, such as change in context and leadership rules, influence global- and individual-level dynamics (e.g., Stevens \& Galloway, 2014).

\section{Local Dynamics}

Our selection of manuscripts that fitted the local dynamics cluster mostly concerned individual centrality in network structures (i.e., the strength and 
Table 3. Approach and Techniques Used on the Reviewed Articles.

\begin{tabular}{|c|c|}
\hline & $n(\%)$ \\
\hline Connectionism & I (0.5) \\
\hline Artificial neural networks & I (0.5) \\
\hline Displaying information & $4 I(2 I .2)$ \\
\hline Multidimensional scaling & I $(0.5)$ \\
\hline Social networks & $37(19.2)$ \\
\hline T-patterns & $2(1.0)$ \\
\hline Voronoi diagrams & I (0.5) \\
\hline Linear or near to linearity description and prediction & $78(40.3)$ \\
\hline ANOVA & $20(10.4)$ \\
\hline ANCOVA & I $(0.5)$ \\
\hline Cluster analysis & $3(1.6)$ \\
\hline $\begin{array}{l}\text { Discontinuous mixed-effect models for cross-level } \\
\text { interactions }\end{array}$ & I (0.5) \\
\hline Linear discriminant analysis & $\mathrm{I}(0.5)$ \\
\hline Linear regression & $10(5.2)$ \\
\hline Logistic regression & I $(0.5)$ \\
\hline MANOVA & I $(0.5)$ \\
\hline Mann-Whitney $U$ test & I $(0.5)$ \\
\hline Multinomial logistic regression & I $(0.5)$ \\
\hline OLS regression & $2(1.0)$ \\
\hline Pearson correlation & $16(8.3)$ \\
\hline Polynomial regression & I $(0.5)$ \\
\hline Random coefficient modeling & $3(1.6)$ \\
\hline Relative phase analysis & $4(2.1)$ \\
\hline Stepwise logistic regressions with a bootstrap & $\mathrm{I}(0.5)$ \\
\hline Stretch index metric & I $(0.5)$ \\
\hline SEM & I $(0.5)$ \\
\hline$t$ test & $8(4.1)$ \\
\hline Ward method with Euclidean distance & $\mathrm{I}(0.5)$ \\
\hline NDS theory & $27(13.9)$ \\
\hline Bifurcation (transition points between states) & $2(1.0)$ \\
\hline Catastrophe modeling & $3(1.6)$ \\
\hline Cross-fuzzy entropy & $\mathrm{I}(0.5)$ \\
\hline Cross-recurrence quantification analysis & I $(0.5)$ \\
\hline Entropy & $9(4.7)$ \\
\hline Fuzzy & $2(1.0)$ \\
\hline Hurst exponents & $\mathrm{I}(0.5)$ \\
\hline Linear autoregression functions & $\mathrm{I}(0.5)$ \\
\hline
\end{tabular}


Table 3. (continued)

\begin{tabular}{lc}
\hline & $n(\%)$ \\
\hline Lyapunov exponents & $5(2.6)$ \\
Phase space analysis & $2(1.0)$ \\
Nondeterministic approach & $5(2.5)$ \\
Lag distributions or sequential analysis & $1(0.5)$ \\
Lag sequential analysis & $1(0.5)$ \\
Markov analysis & $1(0.5)$ \\
Monte Carlo simulations & $2(1.0)$ \\
Probabilistic approach & $9(4.6)$ \\
Bivariate Poisson distribution & $1(0.5)$ \\
Centroid estimation & $7(3.6)$ \\
Percent recurrence & $1(0.5)$ \\
Simulation & $5(2.6)$ \\
SIENA & $1(0.5)$ \\
Surrogate data & $3(1.6)$ \\
Specific kind of simulation & $1(0.5)$ \\
Time series & $27(13.9)$ \\
ARIMA & $1(0.5)$ \\
Synchronization coefficient $S_{E}$ & $1(0.5)$ \\
Spectral analysis & $1(0.5)$ \\
Time-lagged logistic model & $2(1.0)$ \\
Time series analysis & $22(11.4)$ \\
Total & $193(100.0)$ \\
\hline
\end{tabular}

Note. OLS = ordinary least squares; SEM = structural equation modeling; NDS = nonlinear dynamical systems; SIENA = simulation investigation for empirical network analysis; ARIMA = autoregressive integrated moving average.

number of links received from other individuals in a social network; Contractor, DeChurch, Carson, Carter, \& Keegan, 2012). Our review shows that information flow, demographics, values, personality, knowledge expertise, or hormone levels predict team members' centrality in their social network (e.g., Kaonga et al., 2013; Klein et al., 2004; Palazzolo, 2005; Ponzi, Zilioli, Mehta, Maslov, \& Watson, 2016). Learning how individuals acquire centrality in their social networks is of value to understanding how key team phenomena - such as informal leadership - emerge and develop, and how they influence teamwork processes and outcomes. Research by Sarker, Ahuja, Sarker, and Kirkeby (2011) and Sarker, Sarker, Kirkeby, and Chakraborty (2011) suggests that the extent to which information flows in a network predicts centrality, and team member performance depends on 
whether a trustworthy individual occupies a central role in the network (i.e., trust centrality). Sarker, Sarker, et al. (2011) further found that for high-trust centrality, communication highly impacts team member performance, whereas low-trust centrality leads to poor team member performance. Besides trust, Klein et al. (2004) found that whereas education and emotional stability predict team member centrality in a team's advice, friendship, and adversarial network, similarity in personal values such as hedonism and tradition predicts centrality in advice and friendship networks. Also, worth mentioning is Ponzi et al.'s (2016) complementing extant team network centrality research by considering the role of physiological markers, which show how team member popularity and degree of team interconnection depend on basal testosterone and cortisol levels.

Leadership has been examined as a complex phenomenon. By combining a longitudinal design with social network analysis, Emery, Calvard, and Pierce (2013) reported how different team members emerged and disappeared as informal leaders over time, and how members' traits (e.g., extraversion) influence their nomination as informal leaders. In addition, Fransen et al. (2015) revealed that regardless of formal leadership, informal leadership emerges via informal leaders engaging in motivational and social behaviors. Besides that, Long and Siau (2007) suggested that network structures in software development teams evolve from a centralized single-core structure, to a layered structure with multiple cores. As the network grows, an increasing number of core individuals communicate more and facilitate management, evidencing self-organization.

\section{Global Dynamics}

The papers falling within this cluster examined team processes (e.g., coordination), and emergent $\operatorname{states}^{6}$ (e.g., cohesion), and group outcomes (i.e., performance). We briefly synthesized research on each category.

\section{Group processes}

Adaptation. Team adaptation has been conceptualized as a nonlinear, discontinuous process. Barth, Schraagen, Schmettow, and Apperley (2015) examined team adaptation in surgical teams observing structural network communication changes. They reveal that for noncomplex tasks, team communication networks became centralized and less interdependent, whereas under complex problem-solving tasks, communication networks became decentralized, enhancing information exchange. Interestingly, however, the frequency of communication events was lower in complex tasks than in simpler tasks (i.e., evidence of implicit coordination; Rico, Sánchez-Manzanares, 
Gil, \& Gibson, 2008). Adopting a multiphasic approach (Marks, Mathieu, \& Zaccaro, 2001), Barth et al. (2015) also showed that network density and reciprocity were higher during transition phases (i.e., when teams prepare to perform) compared with action phases (i.e., when teams actually perform), and that there is more information sharing during transition phases than action phases, as recent developments in team adaptation predict (Rico, Gibson, Sánchez-Manzanares, \& Clark, 2014).

Considering team learning as part of the team adaptation process, Burke, Stagl, Salas, Pierce, and Kendall (2006) and Rebelo, Stamovlasis, Lourenço, Dimas, and Pinheiro (2016) found that team learning is better described as a discontinuous process (i.e., cusp catastrophe), rather than a continuous process (linear). Furthermore, Paletz, Kim, Schunn, Tollinger, and Vera (2013) found that team learning helps team members to improve their routine and adaptive expertise and that current levels of such expertise are the best predictors of future team performance.

Team coordination. Regarding team coordination, Bourbousson, R'Kiouak, and Eccles (2015) revealed that while expert team members use more implicit coordination processes (i.e., coordination based on anticipation and proactive behavioral change; Rico et al., 2008) and are less aware of other team members when the team is performing, novice team members engage in more explicit coordination process (i.e., coordination based on communication and planning) and are more aware of each other. Bourbousson et al. (2015) also reported a contagion phenomenon on basketball teams: When dyads are tightly coupled (i.e., both members are aware of the behavior of the other), it is easier for a third member to engage with the dyad to constitute a triad.

Further to this, Aubke, Wöber, Scott, and Baggio (2014) found that social network connectedness is influenced by the volume of resources flowing through specific team members. In addition, they report that team cohesion and performance levels depend on team members' expertise and information sharing engagement (i.e., explicit coordination) during task performance. In addition, Mundt et al. (2015) found that the communication networks of health care teams which were decentralized with a higher density of team member interactions had fewer urgent care and emergency department visits, and were more efficient in medical cost per patient over 12 months. Such findings support the CAS notion of teams as self-organizing entities that explicitly coordinate to effectively adapt.

Finally, Gorman, Amazeen, and Cooke (2010) suggested that changes in team coordination over time depend on team stability. Thus, intact teams (i.e., teams who worked together longer without changes) displayed exploration and correction behaviors, whereas reconfigured teams displayed only 
exploration strategies for adopting new coordination requirements. Furthermore, reconfigured teams were more flexible than intact teams and, over time, adopted more new coordination requirements than intact teams. The discovery that reconfigured teams exhibited greater flexibility and adaptive behaviors was possible due to the use of NDS techniques (Gorman et al., 2010).

Team movement. Movement research is a common theme in sport science emerging in our review and offers a complementary view to the study of teams as CAS. Researchers in this area are interested in using individual and collective movement features to predict team behavior (e.g., change in team member trajectory) and team outcomes (e.g., score in a match). Data collection in such studies comes from video and GPS signal recordings, and analyses are done using both linear (e.g., $t$ tests) and nonlinear analytical methods (e.g., Voronoi diagrams; Fonseca, Milho, Travassos, \& Araújo, 2012). For example, Travassos, Araújo, Vilar, and McGarry (2011) studied the emergence of subgroup networks in water polo teams during game play, and found that interaction peaks aggregated around a preferential attachment player who is the key decision maker during the game. Furthermore, Camerino, Chaverri, Anguera, and Jonsson (2012) found that during football (i.e., soccer) games, using a T-patterns approach (i.e., T-patterns are temporal patterns of interactive behavioral chains governed by structures of variable stability that can be visualized; for further detail on how to use it and its application within the team setting, see Magnusson, Burgoon, \& Casarrubea, 2016) allows team players' movement and game play to be detected, and can also predict which interactions lead to better goal opportunities and scores. Thus, T-patterns interaction reveals how in team sports behavior is more synchronized than it appears, and that regularities in playing styles exist. To further this idea, Corrêa, Alegre, Freudenheim, Santos, and Tani (2012) investigated the adaptive process of futsal (i.e., indoor soccer) teams, identifying intrateam and interteam patterns for both attack and defense plays, with nonlinear dynamics. Corrêa et al. observed that intrateam dynamics were aimed at reducing discrepancies and increasing stability during defense phases, whereas during attack phases, the dynamics were aimed at increasing defense destabilizing dynamics. Finally, research by Esteves et al. (2015) showed that the way interpersonal distance changes between attackers and defenders in football (i.e., soccer) influenced the possibilities of converting a shot into an actual goal.

Group emergent states. One of the greatest challenges in teamwork research is to measure and characterize the dynamics of team emergent states (e.g., 
team cohesion). Framing teams as CAS and consequently combining linear and nonlinear analytical methods with the study of emergent states might be a way to significantly expand what we know about how emergent states form, change, and deactivate. An illustrative example is the research on team brain activity using electroencephalography (EEG) signals (e.g., Likens, Amazeen, Stevens, Galloway, \& Gorman, 2014). Using an EEG-derived measure of engagement (termed neurophysiological synchronies of engagement), Stevens, Gorman, Amazeen, Likens, and Galloway (2013) found that periods of up to $10 \mathrm{~min}$ of team cognitive reorganization occurred naturally around stressful teamwork events and following external perturbations. Such reorganizations were structured around episodes of communication, and occurred less frequently in experienced teams. From a similar approach, another topic in our review is physiological-behavioral coupling or how teammates' physiological signals (e.g., heartbeats) became synchronized with the passing of time (e.g., Guastello, Peressini, et al., 2016). Along these lines, Mønster Håkonsson, Eskildsen, and Wallot (2016) found that team members spontaneously synchronize their skin conductance and electromyography (EMG) measures of the corrugator supercilii during cooperative production tasks. Moreover, they found that while high team synchrony signals team cohesion, low team synchrony signals a team decision to adopt new behaviors across multiple performance events.

Finally, Guastello (2007a, 2007b, 2010) has explained how leadership in teams emerges following a nonlinear distribution using catastrophe models. Guastello has described the emergence of leaders as an abrupt event where individuals assume, or renounce the role of leader in a nonlinear way. In addition, Guastello also established a relationship between leadership as a cusp catastrophe, a specific example of nonlinear behavior, and team performance.

\section{Team outcomes}

Team performance. Considering team performance as a nonlinear phenomenon has been made possible by adopting NDS techniques, and implies that performance variations do not occur in proportion to the increase or decrease of any predictive variable (e.g., team size), and has nonlinear (i.e., chaotic) variation. For example, Ramos-Villagrasa, Navarro, and GarcíaIzquierdo (2012) combined linear and nonlinear methods to examine the performance dynamics of Spanish league basketball teams over 12 seasons. They found that the team performance change pattern fluctuated over time by exhibiting a deterministic variation, where top-performing teams displayed a specific fluctuation pattern (i.e., low-dimensional chaos, see below). This study empirically supported team performance nonlinearity, and revealed that chaos, rather than stability, allows teams to reach their goals over time. 
Chaotic dynamics and healthy variability. Interestingly, during the review, we found a phenomenon called healthy variability, which follows from physiology research and is adopted to describe an optimum state of variability in a complex system that predicts optimal performance (Navarro \& Rueff-Lopes, 2015). Using the notion of healthy variability, Correia, Araújo, Davids, Fernandes, and Fonseca (2011) studied sport teams performance through team movement dynamics (i.e., distance gained between defending and attacking teams during rugby games). They found that the amplitude (variability) of movements positively predicts the effectiveness of team attacking, while entropy levels in players' movements (i.e., the rate of information loss in a time series as a consequence of chaotic behavior; Pincus, 2006) were negatively related to attacking effectiveness.

Additional support for the healthy variability notion came from the studies conducted by Likens et al. (2014) when analyzing the impact of EEG data patterns on team processes and outcomes. Likens et al. used multifractal analysis (i.e., a dynamical systems tool that is specifically designed to extract patterns across levels of analysis) to examine team cognitive activity during team communication. Their findings show that smooth fractal dynamics (i.e., smoothly running systems in which the nested physiological or cognitive components interact efficiently) predict team strategy adaptation and coordination over time, while breakdowns in fractal dynamics predict team malfunctioning. Finally, following the same idea of healthy variability, Curral, Marques-Quinteiro, Gomes, and Lind (2016) found that higher team efficiency is achieved in teams where a moderate number of team members display behaviors facilitating information flow and idea implementation between team members, whereas teams that had extremely high or low numbers of individuals performing such behaviors were less effective.

\section{Contextual Dynamics}

Studying the contextual dynamics of teams as CAS requires understanding how contextual factors such as environmental uncertainty or hierarchy influence individual and collective phenomena (e.g., team coordination). With this in mind, Stevens and Galloway (2014) examined how contextual change modifies team neurodynamics (i.e., the nonlinear dynamics resulting from the quantitative coexpression of an EEG-cognitive marker of different team members). They tested the assumption that raw EEG fluctuations (e.g., frequency) may contain statistical regularities expressing task and team actions that might be important for team functioning. Their results suggest that contextual disturbances affected a team's neurodynamic organization, with 
rigidity (i.e., linear dynamics) or high fluidity (i.e., random dynamics) leading to poor team neurodynamic organization.

While these findings might lead us to consider classical U-shaped phenomena, the chance to examine the possible nonlinearity of such phenomena enhances the likelihood of there being dynamic variations instead of a fixed pattern. This approach would also be useful for relevant team processes such as motivation, engagement, leadership, or cohesion. On this basis, Curral et al. (2016) studied leadership theory in the lab from a complexity standpoint. They found that different behavioral rules (e.g., defining which leadership behaviors team members should display) led to alternative leadership arrangements and differences in team efficiency. They also found that whereas centralized leadership arrangements (i.e., leadership function is centralized in one member) led to poor team outcomes, decentralized leadership arrangements (i.e., leadership function is shared by team members) led to improved team self-organization and higher team efficiency.

Arrow et al.'s (2000) three levels of causal dynamics guided our narrative along this section. Next, we move to describe theoretical and methodological guidelines aimed to help researchers in the study of teams as CAS.

\section{Studying CAS From NDS Theory: A Field Guideline}

If we have been persuasive enough, some readers will be wondering how to incorporate NDS in their team research. To assist in this endeavor, we devote this section to providing support in three main areas: (a) theoretical approach, (b) research design, and (c) data collection and data analysis. We elaborate on each of these below. In any event, if the reader needs a more accessible introduction to NDS, we recommend books by Abraham and Shaw (1992) or Briggs and Peat (1990).

\section{Theoretical Approach}

Characterizing teams as CAS requires noting that teams have one or more of the characteristics of complex behavior exhibited in Table 4. As has been sufficiently substantiated in our review, ample research supports the use of the CAS approach in team research, with the study of nonlinear relationships being among the variables of interest, as well as the study of chaos in their dynamic, or the emergent appearance of some team states. Accordingly, a CAS approach can be used to build team theories that address what the constructs are, how and why they are related, where and when the constructs are 
Table 4. Complex Behavior Characteristics and Empirical Examples From Team Science.

\begin{tabular}{|c|c|c|}
\hline Characteristic & Definition & Example \\
\hline $\begin{array}{l}\text { Nonlinear } \\
\text { relationships }\end{array}$ & $\begin{array}{l}\text { The variables of interest not } \\
\text { always keep the proportionality } \\
\text { (e.g., small change on one } \\
\text { variable can have a great impact } \\
\text { on another one). }\end{array}$ & Passos et al. (2009) \\
\hline Chaotic dynamics & $\begin{array}{l}\text { The variable shows a temporal } \\
\text { dynamic with aperiodic and } \\
\text { restricted values, which appear } \\
\text { to behave stochastically } \\
\text { (i.e., they are apparently } \\
\text { nondeterministic) when in } \\
\text { fact their development is } \\
\text { determined by rules and is } \\
\text { predictable to some degree. }\end{array}$ & $\begin{array}{l}\text { Gorman, Hessler, } \\
\text { Amazeen, Cooke, and } \\
\text { Shope }(2012)\end{array}$ \\
\hline Fractal structure & $\begin{array}{l}\text { The system under study is } \\
\text { multilevel and shows a self- } \\
\text { repeating pattern across } \\
\text { different levels (e.g., a variable at } \\
\text { team level has an equivalent one } \\
\text { at individual or organizational } \\
\text { level). }\end{array}$ & $\begin{array}{l}\text { Likens, Amazeen, Stevens, } \\
\text { Galloway, and Gorman } \\
(2014)\end{array}$ \\
\hline $\begin{array}{l}\text { Catastrophic } \\
\text { change }\end{array}$ & $\begin{array}{l}\text { The variable has a relatively stable } \\
\text { behavior followed by a sudden } \\
\text { change. }\end{array}$ & $\begin{array}{l}\text { Rebelo, Stamovlasis, } \\
\text { Lourenço, Dimas, and } \\
\text { Pinheiro (2016) }\end{array}$ \\
\hline $\begin{array}{l}\text { Emergence of } \\
\text { new properties }\end{array}$ & $\begin{array}{l}\text { The system shows a characteristic } \\
\text { developed by interactions } \\
\text { at a lower level where this } \\
\text { characteristic does not exist } \\
\text { (e.g., team performance dynamic } \\
\text { emerges from the interaction } \\
\text { among members). }\end{array}$ & $\begin{array}{l}\text { Ramos-Villagrasa, Navarro, } \\
\text { and García-Izquierdo } \\
(2012)\end{array}$ \\
\hline
\end{tabular}

applicable, and to whom (Whetten, 1989). In our opinion, considering teams as CAS means taking special care regarding the questions of what, how and why, and when and whom. Let us develop these ideas.

What are the team constructs from a CAS perspective? Considering teams as CAS requires embracing the idea of fuzzy sets. Accordingly, the main construct involved here is the team concept itself, and it is easy to see how the 
science of teams paid a lot of attention to defining it. For example, McGrath (1984) had already defined teams as fuzzy sets in the sense that there are some imprecisions, for example, in the degree of members' awareness about their sense of belonging to the team, in the exact number of members on the team, in the range of behavior and situations in which members are interdependent, and so on. All the current literature about groupness or entitativity is devoted to these fuzzy properties in teams (Meneses, Ortega, Navarro, \& de Quijano, 2008). And the ongoing discussion about the differences between work groups and teams (Kozlowski \& Bell, 2003) can be understood as a tacit recognition of the fuzzy nature of team phenomenon.

How and why are the constructs related? Understanding teams as CAS entails thinking in a nonlinear way to build theories and relate them to the constructs involved. At this point, team literature is still anchored in formulating research questions hypothesizing that one variable will be linearly positively or negatively related to another (e.g., more of X will be related to more of Y). Team theory should evolve to propose and study a more fine-grained relationship among variables, for example, clarifying tipping points, or proposing the existence of third variables to show how other variables interrelate. In this regard, when studies introduced third variables (e.g., task interdependence) thus altering the cohesion-team performance relationship (e.g., Beal, Cohen, Burke, \& McLendon, 2003), research concerning cohesion and performance tangibly progressed.

When are the constructs applicable? In our opinion, this is the most neglected question in current team literature. Despite the existence of very widely cited research about time and teams, such as the studies about temporal influences in project teams by Gersick $(1988,1989)$, the model about team socialization by Moreland and Levine (1982; Levine \& Moreland, 1994), or the wellknown book written by McGrath and Tschan (2004), the science of teams could do better. By definition, all team processes and emergent states have a beginning, development, and ending, and team research should be able to trace these temporal dynamics (McGrath \& Tschan, 2004). As we will discuss later, this has important consequences for research designs, and for theory building. We need theories that incorporate temporal dynamics in the processes or states of interest, and theories that propose when things happen, how they change over time, and why. Tackling these issues will greatly develop team science.

Who are the constructs applicable to? The last key aspect to consider in the generation of team theories should take into account the fact that not all teams 
are equal. The existing typologies (e.g., project teams, top management teams, crews, virtual teams, etc.) provide a starting point for theory building. However, we believe we should move forward acknowledging that each team is unique in some way. Just as individual psychology is moving to consider the nonergodicity (i.e., each item of psychological data is always a combination of person, situation, and time: the person is not always the same across situations and across different times) nature of its phenomena of interest (Molenaar, 2004), team research should do the same. The study of a team as a CAS requires a focus on the intrateam level because teams are not homogeneous (i.e., behave in a same way), and not stationary (i.e., not all teams evolve in the same way over time). To paraphrase Molenaar (2004): As psychosocial processes like cohesion, leadership, performance, and so on, occur in real time at the team level, we could define them as team specific. Thus, to retrieve more sensitive theory building about the idiographic characteristics of teams would be commendable.

\section{Research Design and Data Collection}

The theory of teams as CAS highlights time as an essential component of team behavior, consequently the use of time series is highly recommended (e.g., longitudinal research designs). To identify trends in the variables, we need to be sure that the time series cover all parts of the underlying dynamics. Depending on our research purposes, from two different moments of measurement (e.g., catastrophe models applied before and after a transition-produced event), we would need more than 50 data points (e.g., to use Lyapunov exponents; Guastello \& Gregson, 2011). In addition, the time lag (i.e., the time separation between the measures) is just as important as the measurement frequency. Focusing on intrateam changes requires that measures be done considering the expected variability of the construct of interest. For example, it seems reasonable to consider team mental models as a more stable construct than team situational models (Rico et al., 2008). Thus, each variable will require a different measurement time scale according to the rate change of the different variables investigated (e.g., Zaheer, Albert, \& Zaheer, 1999). Exceptionally, cross-sectional designs may also be used, particularly when we analyze the increase in explained variance of a nonlinear model compared with traditional linear models (e.g., Rebelo et al., 2016).

\section{Data Analysis}

Frequently, the first thing researchers read about nonlinear dynamics is the kind of analyses carried out. Analyzing complex behavior requires alternative 
Table 5. NDS Analyses and R Package Component.

\begin{tabular}{|c|c|c|}
\hline NDS analysis & Purpose & $\mathrm{R}$ package \\
\hline Catastrophe models & $\begin{array}{l}\text { Make predictions using few but } \\
\text { relevant variables }\end{array}$ & cusp $^{a}$ \\
\hline Correlation dimension & $\begin{array}{l}\text { Identify the minimum variables } \\
\text { necessary to describe the } \\
\text { system }\end{array}$ & nonlinearTseries \\
\hline Entropy & $\begin{array}{l}\text { ApEn / Samp-En: Identify the } \\
\text { pattern of a time series } \\
\text { Cross-ApEn / Cross-Samp-En: } \\
\text { Analyze similarities among } \\
\text { two time series }\end{array}$ & pracma $^{b}$ \\
\hline Hurst exponent & $\begin{array}{l}\text { Identify the pattern of a time } \\
\text { series }\end{array}$ & liftLRD \\
\hline $\begin{array}{l}\text { Maximum Lyapunov } \\
\text { exponent }\end{array}$ & $\begin{array}{l}\text { Identify the pattern of a time } \\
\text { series }\end{array}$ & nonlinearTseries \\
\hline $\begin{array}{l}\text { Markov chain sequential } \\
\text { data analysis }\end{array}$ & $\begin{array}{l}\text { Specifies the chances that an } \\
\text { event causes another }\end{array}$ & markovchain \\
\hline Phase space analysis & $\begin{array}{l}\text { Identify regularities in a time } \\
\text { series }\end{array}$ & nonlinearTseries \\
\hline Recurrence plots & $\begin{array}{l}\text { Identify regularities in a time } \\
\text { series }\end{array}$ & nonlinearTseries \\
\hline
\end{tabular}

aOnly for cusp catastrophe.

bOnly for ApEn.

ways to deal with data, but theoretical support to use NDS analyses is necessary. In this section, we give an overview and several recommendations for analyzing data using NDS.

Overall recommendations. Until enough evidence is accumulated to ensure the characteristics of teams as CAS (e.g., nonlinear relationships, chaotic dynamic, etc.), researchers should verify that their data exhibit at least one complex pattern property (see Table 4). For example, Ramos-Villagrasa et al. (2012) conducted three analyses to guarantee that their teams presented a complex behavior pattern (maximum Lyapunov exponent estimation-an indicator of chaos; recurrence plots - a visual way to identify nonlinear dynamics; and surrogate data testing - a nonlinear analysis performed to discard random dynamics). Thus, if data do not exhibit a complex pattern, then we may better proceed with traditional analytical approaches (e.g., growth modeling). In any case, the use of NDS analysis could complement other kinds of analysis. For example, Gorman, Hessler, Amazeen, Cooke, and 
Shope (2012) used NDS to detect team communication perturbations, and regression analysis to test whether such perturbations impacted on communication dynamics.

Regarding data analysis itself, we recommend the use of $\mathrm{R}$ software (www.r-project.org). $\mathrm{R}$ is a free software, based on open source, and runs on a wide variety of platforms (Linux, Windows, MacOS). R provides many statistical techniques available in other commercial programs but has two main advantages over them when NDS analyses are needed. First, R can handle various databases simultaneously, a highly recommended property if we consider each team as unique, and second, $\mathrm{R}$ allows the installation of updated packages developed by an active online community that constantly incorporates new features for running NDS analyses. In this regard, Table 5 shows the correspondence of different analyses and the R package supporting them. As an alternative, MatLab also has many ways to perform these analyses and another extensive online sharing community committed to this approach. Finally, it is also possible to use the syntax options in the very wellknown SPSS (e.g., Guastello \& Gregson, 2011, Chapters 3 and 12). Irrespective of the software used, below we describe briefly some specific nonlinear techniques particularly useful for team research.

Catastrophe modeling. Catastrophe theory is focused on the study of discontinuous, abrupt changes in dependent variables resulting from small and continuous changes in independent variables (Guastello, 2013). Several catastrophe models can be identified depending on their geometric appearance (e.g., cusp or butterfly), and depending on the number of dependent and independent variables involved (i.e., parameters). Cusp catastrophe, the most commonly used in team research, describes change between two stable states of the dependent variable (i.e., order parameter) and two independent variables (i.e., control parameters; Ceja \& Navarro, 2012). Catastrophe modeling offers several advantages over traditional linear analysis. It focuses on process dynamics, including discontinuous change; considers nonlinearity; richly describes the phenomenon under consideration; and includes outliers in the model that are not excluded as measurement error, which is important when teams are analyzed individually (Kauffman \& Oliva, 1994). Thus, it is not surprising that catastrophe models explain more variance than linear analysis when complex behavior is studied (e.g., Guastello, 2002, 2011).

Entropy. There are several entropy measures in the team literature that we briefly detail next. First, ApEn (i.e., approximate entropy; Pincus, 1991) analyzes the patterns contained in a time series. A positive value of entropy is associated with a chaotic pattern, in that the higher the value, the harder it is 
to predict the future values of the time series. Several studies from our review use this approach, especially those involving sport teams. For example, Gonçalves, Marcelino, Torres-Ronda, Torrents, and Sampaio (2016) used ApEn to study professional and amateur sport teams in different situations (e.g., distance to nearest opponent, number of teammates available). Another entropy indicator is Cross-ApEn (i.e., cross approximate entropy) that analyzes similarity among two correlated time series. Values near to zero indicate greater similarity between the time series, suggesting an underlying pattern among them, while higher values suggest dissimilarity between time series.

Hurst exponent. The Hurst exponent is considered both a measure of the chaotic dynamic (i.e., sensitive to initial conditions) and fractality (i.e., multilevel self-similarity). This index shows the degree to which a time series tends to move into a certain set of values. The Hurst exponent has values between 0 and 1 . Where 0.5 is an indicator of random time series, values up to 0.5 indicate that the observed behavior is less frequent over time (antipersistent), and values from 0.5 to 1 indicate that the behavior is more frequent over time (persistent). An application for the Hurst exponent can be found in Likens et al. (2014), showing Hurst exponent differences during team performance.

Maximum Lyapunov exponent. The Lyapunov exponent is a quantitative indicator of the degree to which a time series is sensitive to initial conditions; in other words, it is a measure that reveals the underlying data pattern (i.e., linear, chaos, or random). Similar to entropy, when a time series is linear or near to linearity (i.e., without chaotic behavior), the Lyapunov exponent is zero or less. In other cases, as chaos or random patterns appear, it shows positive values. Following Guastello and Liebovitch (2009), if we convert Lyapunov exponents into fractal dimensions, values around 1 to 2 usually characterize self-organized systems and dimensions greater than 3 represent chaos. Maximum Lyapunov exponent was used in team research to identify data patterns and real-time team communication changes (Gorman et al., 2012; RamosVillagrasa et al., 2012).

Phase space analysis. This is a mathematical space comprising the number of dimensions (i.e., variables) in the system under study (Passos et al., 2009). In the strictest sense, the phase space is not an NDS analysis, but it is frequently used in this context to identify chaotic behavior in the system, including the shape of the "strange attractors" that characterize chaotic dynamics (i.e., regions of the phase space where the system tends to back from time to time, 
usually never to the same point, but close). When using phase space analysis, it is crucial to select an adequate number of variables (e.g., estimating the correlation dimension or Hurst exponent), and to ensure the relevance of such variables in predicting the system behavior. An application of phase space analysis can be found in Passos et al. (2009), which reports three different structures in the phase space of rugby dyads that correspond to three different situations produced during the match.

Recurrence analysis. Like the phase space, the recurrence plot is a graphical display of a time series used to identify whether a time series presents a deterministic (i.e., near to linearity or chaotic) or random pattern. In addition to the recurrence plot, there also are some recurrence quantification analyses that allow us to characterize numerically those plots. Several metrics help to analyze the graphical display, as percentage of determinism (\%DET), which can be used to compare plots and interpret them analytically (e.g., Aks, 2011). Although some quantitative indexes exist, evidence about their performance has not been established. Thus, it is recommended that this indicator be used in combination with others to verify results (e.g., maximum Lyapunov exponent). An example of the application of recurrence plots to team research can be found in the aforementioned Mønster et al.'s (2016) study of skin conductance synchronization among team members.

A deeper and more extensive discussion about NDS analytical techniques falls outside the scope of this study. However, additional guidance and detailed information can be found in Gregson and Guastello (2011) or Heath (2000).

\section{Discussion}

This article reinvigorates the NDS approach to further develop research on teams as CAS. To do so, we systematically review and describe the topography of this research, highlighting the lessons learnt and providing guidelines for designing research and analyzing data using this approach. The legacy of Arrow et al. (2000) has not been sufficiently taken advantage of to further develop the science of teams. Only some of their postulates, such as emergence (captured by the multilevel paradigm; Kozlowski \& Klein, 2000) and dynamics (captured by the longitudinal paradigm; Roe, 2008), have been adopted by team scientists to better understand teams. Ironically, the way the field evolved is different from what Arrow et al. (2000) suggested. Although emergence and dynamics, two core properties of CAS and NDS, are now part of the field's constructs, and team phenomena are widely acknowledged as complex, the research methods being employed by scholars kept team 
science away from nonlinearity and confined within the linear-positivist realm. We hope our contribution will reveal that NDS methods are reliable and valuable to better understand the complexity of teams, and further enrich former discoveries solely relying on linear methods. Our review has some implications for team science theory and practice which deserve further consideration.

\section{Theoretical Implications}

To discuss the theoretical implications of our review, we follow again the multilevel structure of Arrow et al. (2000): local, global, and contextual dynamics.

Local dynamics. CAS comprise a property that should be highlighted at the local level: fractality. Understood as the self-similarity of a variable across levels, fractality provides theoretical support to investigate team-level equivalence of individual or organizational phenomena, while revealing their dissimilarities across levels. The self-similarity of fractal structure implies resemblance, but not 1:1 equivalence. Thus, it is possible that different but similar variables (operating at other levels of analysis) are determining changes in team functioning. For example, the study by Emery et al. (2013) found that informal leadership emerges when teammates engage in motivational and social behaviors. This kind of logic will provide the much-needed theoretical backing to support incipient attempts to extend several explanatory individual models (e.g., motivation or job-demands resources) to team level (Chen \& Kanfer, 2006; Urien, Rico, Demerouti, \& Bakker, 2017).

Global dynamics. In our review, we found a considerable amount of research at this level of analysis. This occurs in part, because the pace of teams and their processes are analyzed at this level. As an intrinsically dynamic approach, NDS seems a reasonable way to understand some of the topics of recent growing interest, such as adaptation or coordination. One indicator of this idea is the great number of empirical articles that we found to describe movement, synchronization, and so on, in sport research (e.g., Corrêa et al., 2012; Esteves et al., 2015). In addition, some of the studies reviewed, like those by Likens et al. (2014) and Espinosa and Clark (2014), led us to think that NDS offers new approaches to well-established team constructs, like team cognition by using EEG and social networks.

Our findings regarding healthy variability warrant additional theoretical discussion, as we consider them one of the most prominent results of our review. It seems desirable that team processes and outcomes are reached 
when the team is able to substantially change (i.e., modify) its behavior in accordance with changing circumstances and demands, yet not so much as to make the team derail. Thus, healthy variability resembles the classic inverted U-shape reported in extant cross-sectional team research suggesting that extremely low or high levels of a variable have a negative impact on a second variable, turning the middle into the optimal point. From a longitudinal approach, healthy variability means also that extremely low or high fluctuations are related to the poorest results (Navarro \& Rueff-Lopes, 2015). Accordingly, healthy variability is a good candidate to be incorporated in team adaptation studies concerned with the optimal range of fluctuation in team processes (e.g., team coordination) yielding positive team adaptive outcomes.

Contextual dynamics. Unlike global dynamics, contextual dynamics remains an issue that deserves more attention in the future. In that sense, considering teams as CAS underlines the need to study the role of initial conditions (i.e., how a team begins) as a determinant of team evolution. For example, the studies using catastrophe models show the impact of initial conditions on the evolution of teams (e.g., Guastello, 2010). Thus, conceptualizing in which situations contextual variables behave as order or control parameters of different team phenomena would lead to interesting insights into contextual dynamics.

\section{Practical Implications}

Our review also has some practical implications both for researchers and practitioners. We articulated these around three main questions: Why is research on teams as CAS not easily accessible? How do linear and nonlinear analytical techniques complement each other? and How can NDS be applied to managing teams?

Why is research on teams as CAS not accessible? Although our review reveals there is ample consensus on theoretically defining teams as CAS, researchers do not study them as such. It is true that research on teams as CAS exists, but why is it hard to find? We believe that one main reason for this is because such research has been developed predominantly by and for a community of "NDS-believers." These community members have marginalized themselves through their own journals (e.g., Nonlinear Dynamics, Psychology, and Life Sciences, called also NDPLS), and by communicating results to an audience that understands and trusts in NDS theory. ${ }^{7}$ As a result, with very few exceptions (e.g., Guastello, 2010), this has created a divide between NDS research applied to teams, and team research in general. 
A second main reason why studying teams as CAS is not so popular, hence reinforcing the divide, is the unfamiliar constructs, and the mathematical logic supporting NDS analysis seeming too complicated to master and interpret (Guastello, 2001). For instance, the collection of NDS constructs and approaches we summarized in previous sections are just a small portion of the techniques used, and illustrate only the most commonly used in the study of teams as CAS. In addition, techniques such as cusp catastrophe modeling or the maximum Lyapunov exponent have a mathematical origin and are expressed in mathematical language, not in qualitative sentences. Thus, this complicates sharing such approaches with a wider audience, and discourages researchers from learning and applying them in their research. However, as our review illustrates, performing research using NDS does not substantially differ from the mainstream approach in team research in terms of analysis, nor from a conceptual point of view.

Some tentative solutions to this issue could be proposed. First, special articles in widely cited journals would expose the field to a greater audience and contribute toward reducing the bias of considering teams as CAS as an obscure and eccentric part of team research. Second, if $\mathrm{PhD}$ students receive training in NDS theorizing and analytical techniques, it will be much easier and more natural for them to use such methods in their research.

How do linear and nonlinear analytical techniques complement each other? One interesting fact that emerged during our review was that authors often combine linear and nonlinear methods to understand the phenomena under research (e.g., social network analysis and linear regression for hypotheses testing). We believe that the analytical techniques utilized under NDS theory are not intended to replace the use of linear analytical approaches, nor they are the holy grail of team science. But, they can truly add valuable knowledge to what we already know (and may know) about teamwork.

To illustrate our point, let us take the relationship between team coordination and performance, and imagine that we want to know how team coordination leads to better team performance. Using ANOVAs and $t$ tests, we could find team mean differences for a given absolute value. For instance, we could reveal whether initial conditions such as group size ( $n=4$ vs. $n=9)$ can explain differences in team members' capacity to plan the team task and share information (i.e., to explicitly coordinate), and in team performance. However, ANOVAs and $t$ tests do not provide information about the dynamics of coordination and performance when there are different initial team sizes. Thus, ANOVAs and $t$ tests ignore the abrupt change that so often characterizes team reality, at least if we do not use extreme group designs (Guastello, 2001). If a cusp catastrophe model is additionally used to analyze 
data, researchers can learn under which values of coordination and team size, team performance suddenly and dramatically improves or diminishes (Guastello, 2013). Furthermore, using a Lyapunov exponent will reveal how chaotic (i.e., sensitive to system initial condition) a team is. For instance, optimum team performance levels could be determined when coordination presents a low-dimensional chaotic variation, and worst team performance levels when coordination presents linear and random variation (e.g., Guastello \& Guastello, 1998).

How can NDS be applied to managing teams? While some may sound more feasible than others, our review reveals how NDS theory could be applied to manage teams. For example, to the extent that an electrocardiogram shows the nonlinearity of a heart beating and provides information on patients' health allowing doctors to take the necessary actions; the collection of individual team members' EEGs might also be useful to inform about the quality of team member interactions and predict team breakdowns during training or real task assignments (Likens et al., 2014). Under synchronous EEG activity, coordination could unfold smoothly, whereas asynchronous EEG activity might signal an upcoming disruption in teamwork (Likens et al., 2014). The same reasoning goes for skin conductance and EMG, which have been shown to be good predictors of team performance in production tasks (Mønster et al., 2016). Future wearable devices will make gathering and using these kinds of psychophysiological markers natural.

Another practical application of NDS techniques to team management could be predicting variations in team performance by means of cusp catastrophe modeling. Following cusp catastrophe modeling, it could be argued that the extent to which team performance will change abruptly can be predicted by at least two parameters (independent variables): asymmetry parameters and bifurcation parameters (Guastello, 2013). Asymmetry parameters are responsible for smooth data distributions, and predict linear changes in the dependent variable (Zeeman, 1976). A good candidate as asymmetry parameters are team processes, which have been systematically shown to be positively and linearly related with team performance (LePine, Piccolo, Jackson, Mathieu, \& Saul, 2008). Bifurcation parameters are responsible for discontinuity, and do not correlate with the outcome variable (Zeeman, 1976). Differently from asymmetry variables, control parameters cause discontinuities in data distribution and cause data bimodality (i.e., data distribution is polarized, with most cases concentrating on two extremes). Following research on team diversity faultlines (e.g., Meyer, Glenz, Antino, Rico, \& González-Romá, 2014), it could be argued that faultlines are a bifurcation parameter predicting chaotic distribution in team performance under cusp 
catastrophe modeling. Thus, using catastrophe models, managers may predict at which exact values of team processes and team faultlines team performance will display catastrophic variation (Guastello, 2013).

\section{Conclusion}

The science of teams is a multidisciplinary field, and understanding teams as CAS can make a great contribution toward team scientists' speaking a common language. As the interest in temporal issues on teams steadily grows, it becomes ever more necessary to find ways to deal with phenomena that do not behave in a stable way over time. In this endeavor, NDS allows us to better understand team functioning. NDS is more than just a new fancy set of methods; it is a change in the way we conceptualize teams, and the closest way to be faithful to McGrath et al.'s (2000) proposition. It is our hope that the next 17 years will bring the maturation of teams as CAS.

\section{Authors' Note}

The first author belongs to "Grupo de Estudios de la Sociedad del Riesgo," a research team supported by the Government of Aragon, Spain (Ref. S45).

\section{Declaration of Conflicting Interests}

The author(s) declared no potential conflicts of interest with respect to the research, authorship, and/or publication of this article.

\section{Funding}

The author(s) disclosed receipt of the following financial support for the research, authorship, and/or publication of this article: Spanish National Plan for R\&D, Ministry of Economy and Competitiveness (PSI2012-31135, R. Rico, Principal Investigator, and PSI2013-44854-R project, P. J. Ramos-Villagrasa and J. Navarro, Investigators) for support that, in part, assisted the composition of this article. William James Center for Research, ISPA - Instituto Universitário is financed by Fundação para a Ciência e a Tecnologia (FCT; Ref. UID/PSI/04810/2013).

\section{Notes}

1. Search done in April 26, 2017.

2. We use the term linear to describe those approaches sustained on the general linear model or similar, where proportionality among the variables involved is expected. However, nonlinearity comprises a set of possible relationships where proportionality does not always exist. When we embrace nonlinearity, we are open to using different approaches that analyze phenomena as they are, instead of trying to fit them into a straight line (Begun, 1994). 
3. Team was defined as "two or more people who interact dynamically, interdependently, and adaptively, toward a common and valued goal/object/mission, who have each been assigned specific roles or functions to perform, and who have a limited life span of membership" (Salas, Dickinson, Converse, \& Tannenbaum, 1992, p. 4). Thus, dyads are qualified as work teams as well in the present article.

4. We included fuzzy sets in our review. However, following suggestions by an anonymous reviewer, we remove it for the final version of the article because although sometimes it is considered part of nonlinear dynamical systems (NDS) framework (see Meyers, 2009), it follows a different rationale. Nevertheless, we keep the keyword and the results for the sake of replicability.

5. The complete list of authorships, institutions, journals, keywords, and research variables is available upon request to the corresponding author.

6. Following Marks, Mathieu, and Zaccaro (2001) conceptualization of (a) team processes as "team members' interdependent acts that convert inputs to outcomes through cognitive, verbal, and behavioral activities directed toward organizing task work to achieve collective goals" (p. 357); and (b) emergent states as "constructs that characterize properties of the team that are typically dynamic in nature and vary as a function of team context, inputs, processes, and outcomes" (p. 357).

7. We agree with an anonymous reviewer who noted that Nonlinear Dynamics, Psychology, and Life Sciences (NDPLS) has positioned itself as the place where the cutting edge of nonlinear science occurs, at least for all areas outside of physical systems. When the journal was started, potential authors had a serious concern that editors and reviewers of conventional journals reject manuscripts because they do not understand the material. Thus, we are in a bind due to a situation of shared guilt: On the one hand is the traditional science which is tied to its first principles and on the other, NDS researchers who are not able to successfully communicate their approach.

\section{References}

References marked with an asterisk indicated studies included in the review.

Abraham, R., \& Shaw, C. D. (1992). Dynamics: The geometry of behavior (2nd ed.). Boston, MA: Addison-Wesley.

Aks, D. (2011). Analysis of recurrence: Overview \& application to eye-movement behavior. In S. J. Guastello \& R. A. M. Gregson (Eds.), Nonlinear dynamical systems analysis for the behavioral sciences using real data (pp. 231-250). Boca Raton, FL: CRC Press/Taylor \& Francis.

*Amat, C. B., \& Perruchas, F. (2015). Evolving cohesion metrics of a research network on rare diseases: A longitudinal study over 14 years. Scientometrics, 108, 41-56. doi:10.1007/s11192-016-1952-z

Anderson, P., Meyer, A., Eisenhardt, K., Carley, K., \& Pettigrew, A. (1999). Introduction to the special issue: Application of complexity theory to organization science. Organization Science, 10, 233-236. doi:10.1287/orsc.10.3.233 
Arrow, H., McGrath, J. E., \& Berdahl, J. L. (2000). Small groups as complex systems: Formation, coordination, development, and adaptation. Thousand Oaks, CA: SAGE.

*Aubke, F., Wöber, K., Scott, N., \& Baggio, R. (2014). Knowledge sharing in revenue management teams: Antecedents and consequences of group cohesion. International Journal of Hospitality Management, 41, 149-157. doi:10.1016/j. ijhm.2014.05.010

*Avnet, M. S., \& Weigel, A. L. (2012). The structural approach to shared knowledge: An application to engineering design teams. Human Factors, 55, 581-594. doi: $10.1177 / 0018720812462388$

*Bagrow, J. P., \& Klug, M. (2016). Understanding the group dynamics and success of teams. Royal Society Open Science, 3(160007). doi:10.1098/rsos.160007

*Barreira, D., Garganta, J., Castellano, J., Prudente, J., \& Anguera, M. T. (2014). Evolución del ataque en el fútbol de élite entre 1982 y 2010: Aplicación del análisis secuencial de retardos. Revista de Psicologia del Deporte, 23, 139-146.

*Barth, S., Schraagen, J. M., Schmettow, M., \& Apperley, T. H. (2015). Network measures for characterising team adaptation processes. Ergonomics, 58, $1287-$ 1302. doi:10.1080/00140139.2015.1009951

Beal, D. J., Cohen, R. R., Burke, M. J., \& McLendon, C. L. (2003). Cohesion and performance in groups: A meta-analytic clarification of construct relations. Journal of Applied Psychology, 88, 989-1004. doi:10.1037/0021-9010.88

Begun, J. W. (1994). Chaos and complexity: Frontiers of organizational science. Journal of Management Inquiry, 3, 329-335. doi:10.1177/105649269434006

*Bourbousson, J., R'Kiouak, M., \& Eccles, D. W. (2015). The dynamics of team coordination: A social network analysis as a window to shared awareness. European Journal of Work \& Organizational Psychology, 24, 742-760. doi:10.1080/1359 432X.2014.1001977

*Bourbousson, J., Sève, C., \& McGarry, T. (2010a). Space-time coordination dynamics in basketball: Part 1. Intra- and inter-couplings among player dyads. Journal of Sports Sciences, 28, 339-347. doi:10.1080/02640410903503632

*Bourbousson, J., Sève, C., \& McGarry, T. (2010b). Space-time coordination dynamics in basketball: Part 2. The interaction between the two teams. Journal of Sports Sciences, 28, 349-358. doi:10.1080/02640410903503640

Briggs, J. P., \& Peat, F. D. (1990). The turbulent mirror: Illustrated guide to chaos theory and the science of wholeness. New York, NY: Harper \& Row.

Burke, C. S., Stagl, K. C., Salas, E., Pierce, L., \& Kendall, D. L. (2006). Understanding team adaptation: A conceptual analysis and model. Journal of Applied Psychology, 91, 1189-1207. doi:10.1037/0021-9010.91.6.1189

*Camerino, O., Chaverri, J., Anguera, M. T., \& Jonsson, G. K. (2012). Dynamics of the game in soccer: Detection of T-patterns. European Journal of Sport Science, 12, 216-224. doi:10.1080/17461391.2011.566362

Ceja, L., \& Navarro, J. (2012). Suddenly I get into the zone: Examining discontinuities and nonlinear changes in flow experiences at work. Human Relations, 65, 1101-1127. doi:10.1177/0018726712447116 
*Chang, Y. F., Watada, J., \& Ishii, H. (2012). A fuzzy MCDM approach to building a model of high performance project team-A case study. International Journal of Innovative Computing, Information \& Control, 8, 7393-7404.

Chen, G., \& Kanfer, R. (2006). Toward a systems theory of motivated behavior in work teams. Research in Organizational Behavior, 27, 223-267. doi:10.1016/ S0191-3085(06)27006-0

*Clariana, R. B., Engelmann, T., \& Yu, W. (2013). Using centrality of concept maps as a measure of problem space states in computer-supported collaborative problem solving. Educational Technology Research \& Development, 61, 423-442. doi:10.1007/s11423-013-9293-6

Contractor, N. S., DeChurch, L. A., Carson, J., Carter, D. R., \& Keegan, B. (2012). The topology of collective leadership. The Leadership Quarterly, 23, 994-1011. doi:10.1016/j.leaqua.2012.10.010

Cook, D. J., Mulrow, C. D., \& Haynes, R. B. (1997). Systematic reviews: Synthesis of best evidence for clinical decisions. Annals of Internal Medicine, 126, 376-380. doi:10.7326/0003-4819-126-5-199703010-00006

*Corrêa, U. C., Alegre, F. A. M., Freudenheim, A. M., Santos, S., \& Tani, G. (2012). The game of futsal as an adaptive process. Nonlinear Dynamics, Psychology, and Life Sciences, 16, 185-204.

*Correia, V., Araújo, D., Davids, K., Fernandes, O., \& Fonseca, S. (2011). Territorial gain dynamics regulates success in attacking sub-phases of team sports. Psychology of Sport and Exercise, 12, 662-669. doi:10.1016/j.psychsport.2011.06.001

*Curral, L., Marques-Quinteiro, P., Gomes, C., \& Lind, P. G. (2016). Leadership as an emergent feature in social organizations: Insights from a laboratory simulation experiment. PLoS ONE, 11, e0166697. doi:10.1371/journal.pone.0166697

*Da Silva, R., Vainstein, M. H., Lamb, L. C., \& Prado, S. D. (2013). A simple nonMarkovian computational model of the statistics of soccer leagues: Emergence and scaling effects. Computer Physics Communications, 184, 661-670. doi:10.1016/j. cpc.2012.10.030

*Devetag, G., Pancotto, F., \& Brenner, T. (2014). The minority game unpacked: Coordination and competition in a team-based experiment. Journal of Evolutionary Economics, 24, 761-797. doi:10.1007/s00191-014-0351-y

Dooley, K. J. (1997). A complex adaptive systems model of organizational change. Nonlinear Dynamics, Psychology, and Life Sciences, 1, 69-97. doi:10.1023/ A: 1022375910940

*Duarte, R., Araújo, D., Correia, V., Davids, K., Marques, P., \& Richardson, M. J. (2013). Competing together: Assessing the dynamics of team-team and playerteam synchrony in professional association football. Human Movement Science, 32, 555-566. doi:10.1016/j.humov.2013.01.011

*Duarte, R., Araújo, D., Freire, L., Folgado, H., Fernandes, O., \& Davids, K. (2012). Intra- and inter-group coordination patterns reveal collective behaviors of football players near the scoring zone. Human Movement Science, 31, 1639-1651. doi:10.1016/j.humov.2012.03.001 
*Easton, G. S., \& Rosenzweig, E. D. (2015). Team leader experience in improvement teams: A social networks perspective. Journal of Operations Management, 37, 13-30. doi:10.1016/j.jom.2015.05.001

*Emery, C., Calvard, T. S., \& Pierce, M. E. (2013). Leadership as an emergent group process: A social network study of personality and leadership. Group Processes \& Intergroup Relations, 16, 28-45. doi:10.1177/1368430212461835

*Espinosa, J. A., \& Clark, M. A. (2014). Team knowledge representation: A network perspective. Human Factors, 56, 333-348. doi:10.1177/0018720813494093

*Esteves, P. T., Silva, P., Vilar, L., Travassos, B., Duarte, R., Arede, J., \& Sampaio, J. E. (2015). Space occupation near the basket shapes collective behaviours in youth basketball. Journal of Sports Sciences, 34, 1557-1563. doi:10.1080/02640 414.2015.1122825

*Fonseca, S., Milho, J., Travassos, B., \& Araújo, D. (2012). Spatial dynamics of team sports exposed by Voronoi diagrams. Human Movement Science, 31, 1652-1659. doi:10.1016/j.humov.2012.04.006

*Fransen, K., Van Puyenbroeck, S., Loughead, T. M., Vanbeselaere, N., De Cuyper, B., Vande Broek, G., \& Boen, F. (2015). Who takes the lead? Social network analysis as a pioneering tool to investigate shared leadership within sports teams. Social Networks, 43, 28-38. doi:10.1016/j.socnet.2015.04.003

*Frencken, W., Poel, H., De Visscher, C., \& Lemmink, K. (2012). Variability of interteam distances associated with match events in elite-standard soccer. Journal of Sports Sciences, 30, 1207-1213. doi:10.1080/02640414.2012.703783

*García, J., Ibáñez, S. J., Cañadas, M., \& Antúnez, A. (2013). Complex system theory in team sports. Example in 5 on 5 basketball contest. Revista de Psicologia del Deporte, 22, 209-213.

Gell-Mann, M. (1994). The quark and the jaguar. New York, NY: W. H. Freeman.

Gersick, C. J. G. (1988). Time and transition in work teams: Toward a new model of group development. Academy of Management Journal, 31, 9-41. doi: $10.2307 / 256496$

Gersick, C. J. G. (1989). Marking time: Predictable transitions in tasks groups. Academy of Management Journal, 32, 274-309. doi:10.2307/256363

*Gonçalves, B., Marcelino, R., Torres-Ronda, L., Torrents, C., \& Sampaio, J. (2016). Effects of emphasizing opposition and cooperation on collective movement behavior during football small-sided games. Journal of Sports Sciences, 34, 1346-1354. doi:10.1080/02640414.2016.1143111

*Gorman, J. C., Amazeen, P. G., \& Cooke, N. J. (2010). Team coordination dynamics. Nonlinear Dynamics, Psychology, and Life Sciences, 14, 265-289.

*Gorman, J. C., Cooke, N. J., Amazeen, P. G., \& Fouse, S. (2011). Measuring patterns in team interaction sequences using a discrete recurrence approach. Human Factors, 54, 503-517. doi:10.1177/0018720811426140

*Gorman, J. C., Hessler, E. E., Amazeen, P. G., Cooke, N. J., \& Shope, S. M. (2012). Dynamical analysis in real time: Detecting perturbations to team communication. Ergonomics, 55, 825-839. doi:10.1080/00140139.2012.679317

Gregson, R. A. M., \& Guastello, S. J. (2011). Introduction to nonlinear dynamical systems analysis. In S. J. Guastello \& R. A. M. Gregson (Eds.), Nonlinear 
dynamical systems analysis for the behavioral sciences using real data (pp. 116). Boca Raton, FL: CRC Press/Taylor \& Francis.

*Griessmair, M., Strunk, G., Vetschera, R., \& Koeszegi, S. T. (2015). Complexity in electronic negotiation support systems. Nonlinear Dynamics, Psychology, and Life Sciences, 15, 477-511.

Guastello, S. J. (2001). Nonlinear dynamics in psychology. Discrete Dynamics in Nature and Society, 6, 11-29.

Guastello, S. J. (2002). Managing emergent phenomena: Nonlinear dynamics in work organizations. Mahwah, NJ: Lawrence Erlbaum.

Guastello, S. J. (2007a). Non-linear dynamics and leadership emergence. The Leadership Quarterly, 18, 357-369. doi:10.1016/j.leaqua.2007.04.005

Guastello, S. J. (2007b). How leaders really emerge. American Psychologist, 62, 606607. doi:10.1037/0003-066X62.6.606

Guastello, S. J. (2009). Group dynamics: Adaptability, coordination, and the emergence of leaders. In S. J. Guastello, M. Koopmans \& D. Pincus (Eds.), Chaos and complexity in psychology: Theory of nonlinear dynamical systems (pp. 402-433). New York, NY: Cambridge University Press.

Guastello, S. J. (2010). Self-organization and leadership emergence in emergency response teams. Nonlinear Dynamics, Psychology, and Life Sciences, 14, 179-204.

Guastello, S. J. (2011). Leadership emergence in engineering design teams. Nonlinear Dynamics, Psychology, and Life Sciences, 15, 87-104.

Guastello, S. J. (2013). Catastrophe theory and its applications in industrial/organizational psychology. In J. M. Cortina \& R. S. Landis (Eds.), Modern research methods for the study of behaviour in organizations (pp. 29-62). London, England: Routledge.

*Guastello, S. J., \& Bond, R. W. (2007). The emergence of leadership in coordinationintensive groups. Nonlinear Dynamics, Psychology, and Life Sciences, 11, 91-117.

Guastello, S. J., \& Gregson, R. A. M. (2011). Nonlinear dynamical systems analysis for the behavioral sciences using real data. Boca Raton, FL: CRC Press.

Guastello, S. J., \& Guastello, D. D. (1998). Origins of coordination and team effectiveness: A perspective from game theory and nonlinear dynamics. Journal of Applied Psychology, 83, 423-437.

Guastello, S. J., \& Liebovitch, M. (2009). Introduction to nonlinear dynamics and complexity. In S. J. Guastello, M. Koopmans \& D. Pincus (Eds.), Chaos and complexity in psychology: The theory of nonlinear dynamical systems (pp. 1-40). New York, NY: Cambridge University Press.

*Guastello, S. J., Malon, M., Timm, P., Weinberger, K., Gorin, H., Fabisch, M., \& Poston, K. (2014). Catastrophe models for cognitive workload and fatigue in a vigilance dual task. Human Factors, 56, 737-751. doi:10.1177/0018720813508777

*Guastello, S. J., Marra, D. E., Castro, J., Gomez, M., \& Perna, C. (2017). Performance and participation dynamics in an emergency response simulation. Nonlinear Dynamics Psychology \& Life Sciences, 21, 217-250.

*Guastello, S. J., Peressini, A. F., Marra, D. E., Castro, J. V., \& Gomez, M. (2016, July). Team synchronization, coordination, participation, and performance. 
Proceedings of the 26th Annual International Conference of the Society for Chaos Theory in Psychology \& Life Sciences, Salt Lake City, UT.

*Guastello, S. J., Reiter, K. E., \& Malon, M. (2016). Cognitive workload and fatigue in a vigilance dual task: Miss errors, false alarms, and the effect of wearing biometric sensors while working. Nonlinear Dynamics, Psychology, and Life Sciences, 20, 509-535.

Heath, R. A. (2000). Nonlinear dynamics: Techniques and applications in Psychology. Mahwah, NJ: Lawrence Erlbaum.

*Heo, H., Lim, K. Y., \& Kim, Y. (2010). Exploratory study on the patterns of online interaction and knowledge co-construction in project-based learning. Computers \& Education, 55, 1383-1392. doi:10.1016/j.compedu.2010.06.012

*Hwang, S. L., Liang, G. F., Lin, J. T., Yau, Y. J., Yenn, T. C., Hsu, C. C., \& Chuang, C. F. (2009). A real-time warning model for teamwork performance and system safety in nuclear power plants. Safety Science, 47, 425-435. doi:10.1016/j. ssci.2008.07.011

*Jo, I. H. (2009). The effect of social network diagrams on a virtual network of practice: A Korean case. Asia Pacific Education Review, 10, 525-534. doi:10.1007/ s12564-009-9041-0

*Joshi, A., Labianca, G., \& Caligiuri, P. M. (2002). Getting along long distance: Understanding conflict in a multinational team through network analysis. Journal of World Business, 37, 277-284. doi:10.1016/S1090-9516(02)00094-9

*Kaonga, N. N., Labrique, A., Mechael, P., Akosah, E., Ohemeng-Dapaah, S., Sakyi Baah, J., . . Levine, O. (2013). Using social networking to understand social networks: Analysis of a mobile phone closed user group used by a Ghanaian health team. Journal of Medical Internet Research, 15(4), Article e74. doi:10.2196/ jmir. 2332

Kauffman, R. G., \& Oliva, T. A. (1994). Multivariate catastrophe model estimation: Method and application. Academy of Management Journal, 37, 206-221. doi: $10.2307 / 256778$

*Klein, K. J., Lim, B. C., Saltz, J. L., \& Mayer, D. M. (2004). How do they get there? An examination of the antecedents of centrality in team networks. Academy of Management Journal, 47, 952-963. doi:10.2307/20159634

*Koopman, S. J., \& Lit, R. (2015). A dynamic bivariate Poisson model for analysing and forecasting match results in the English Premier League. Journal of the Royal Statistical Society. Series A: Statistics in Society, 178, 167-186. doi:10.1111/ rssa.12042

Kozlowski, S. W. J., \& Bell, B. S. (2003). Work groups and teams in organizations. In W. C. Borman, D. R. Ilgen \& R. J. Klimoski (Eds.), Handbook of psychology: Industrial and organizational psychology (Vol. 12, pp. 333-375). London, England: John Wiley.

Kozlowski, S. W. J., Chao, G. T., Chang, C. H., \& Fernandez, R. (2016). Team dynamics: Using "big data" to advance the science of team effectiveness. In S. Tonidandel, E. King \& J. Cortina (Eds.), Big data at work: The data science revolution and organizational psychology (pp. 273-309). New York, NY: Routledge. 
Kozlowski, S. W. J., \& Klein, K. J. (2000). A multilevel approach to theory and research in organizations: Contextual, temporal and emergent processes. In K. J. Klein \& S. W. Kozlowski (Eds.), Multilevel theory, research, and methods in organizations: Foundations, extensions, and new directions (pp. 3-90). San Francisco, CA: Jossey-Bass.

*Kratzer, J., Leenders, R. T. A. J., \& Van Engelen, J. M. L. (2008). The social structure of leadership and creativity in engineering design teams: An empirical analysis. Journal of Engineering and Technology Management, 25, 269-286. doi:101016/j.jengtecman.2008.10.004

LePine, J. A., Piccolo, R. F., Jackson, C. L., Mathieu, J. E., \& Saul, J. R. (2008). A meta-analysis of teamwork processes: Tests of a multidimensional model and relationships with team effectiveness criteria. Personnel Psychology, 61, 273308. doi:10.1111/j.1744-6570.2008.00114.x

Levine, J. M., \& Moreland, R. L. (1994). Group socialization: Theory and research. In W. Stroebe \& M. Hewstone (Eds.), European review of psychology (Vol. 5, pp. 305-336). London, UK: John Wiley.

Lewin, R. (1993). Complexity: Life at the edge of chaos. London, England: Phoenix.

*Likens, A. D., Amazeen, P. G., Stevens, R., Galloway, T., \& Gorman, J. C. (2014). Neural signatures of team coordination are revealed by multifractal analysis. Social Neuroscience, 9, 219-234. doi:10.1080/17470919.2014.882861

*Long, Y., \& Siau, K. (2007). Social network structures in open source software development teams. Journal of Database Management, 18, 25-40.

Lotka, A. J. (1926). The frequency distribution of scientific productivity. Journal of Washington Academy of Sciences, 16, 317-323.

Magnusson, M. S., Burgoon, J. K., \& Casarrubea, M. (2016). Discovering hidden temporal patterns in behavior and interaction: T-pattern detection and analysis with THEMETM. New York, NY: Springer.

Marks, M. A., Mathieu, J. E., \& Zaccaro, S. J. (2001). A temporally based framework and taxonomy of team processes. Academy of Management Review, 26, 356-376. doi:10.5465/AMR.2001.4845785

Mathieu, J. E., Tannenbaum, S. I., Donsbach, J. S., \& Alliger, G. M. (2014). A review and integration of team composition models moving toward a dynamic and temporal framework. Journal of Management, 40, 130-160. doi:10.1177/ 0149206313503014

McGrath, J. E. (1984). Groups: Interaction and performance. Englewood Cliffs, NJ: Prentice Hall.

McGrath, J. E., Arrow, H., \& Berdahl, J. L. (2000). The study of groups: Past, present, and future. Personality and Social Psychology Review, 4, 95-105.

McGrath, J. E., \& Tschan, F. (2004). Temporal matters in social psychology: Examining the role of time in the lives of groups and individuals. Washington, DC: American Psychological Association.

Meneses, R., Ortega, R., Navarro, J., \& de Quijano, S. D. (2008). Criteria for assessing the level of group development (LGD) of work groups: Groupness, entitativity, and groupality as theoretical perspectives. Small Group Research, 39, 492-514. 
Meyer, B., Glenz, A., Antino, M., Rico, R., \& González-Romá, V. (2014). Faultlines and subgroups: A meta-review and measurement guide. Small Group Research, 45, 633-670. doi:10.1177/1046496414552195

Meyers, R. A. (Ed.). (2009). Encyclopedia of complexity and systems science. New York, NY: Springer.

Molenaar, P. C. M. (2004). A manifesto on psychology as idiographic science: Bringing the person back into scientific psychology, this time forever. Measurement, 2, 201-218. doi:10.1207/s15366359mea0204_1

*Mønster, D., Håkonsson, D. D., Eskildsen, J. K., \& Wallot, S. (2016). Physiological evidence of interpersonal dynamics in a cooperative production task. Physiology \& Behavior, 156, 24-34. doi:10.1016/j.physbeh.2016.01.004

*Montes, F., Sala-Garrido, R., \& Usai, A. (2014). The lack of balance in the Spanish First Division football league. European Sport Management Quarterly, 14, 282298. doi:10.1080/16184742.2014.898678

Moreland, R. L., \& Levine, J. M. (1982). Socialization in small groups: Temporal changes in individual-group relations. In L. Berkowitz (Ed.), Advances in experimental social psychology (Vol. 15, pp. 137-192). New York, NY: Academic Press.

*Moura, F. A., Martins, L. E. B., Anido, R. O., Ruffino, P. R. C., Barros, R. M. L., \& Cunha, S. A. (2013). A spectral analysis of team dynamics and tactics in Brazilian football. Journal of Sports Sciences, 31, 1568-1577. doi:10.1080/0264 0414.2013.789920

*Mundt, M. P., Gilchrist, V. J., Fleming, M. F., Zakletskaia, L. I., Tuan, W.-J., \& Beasley, J. W. (2015). Effects of primary care team social networks on quality of care and costs for patients with cardiovascular disease. Annual Family Medicine, 13, 139-148. doi:10.1370/afm. 1754

Navarro, J., Roe, R. A., \& Artiles, M. I. (2015). Taking time seriously: Changing practices and perspectives in work/organizational psychology. Revista de Psicología del Trabajo y de las Organizaciones, 31, 135-145. doi:10.1016/j. rpto.2015.07.002

Navarro, J., \& Rueff-Lopes, R. (2015). Healthy variability in organizational behavior: Empirical evidence and new steps for future research. Nonlinear Dynamics, Psychology, and Life Sciences, 19, 529-552.

*Noonan, P. M., McCall, Z. A., Zheng, C., \& Gaumer Erickson, A. S. (2012). An analysis of collaboration in a state-level interagency transition team. Career Development and Transition for Exceptional Individuals, 35, 143-154. doi: $10.1177 / 2165143412443083$

*Palazzolo, E. T. (2005). Organizing for information retrieval in transactive memory systems. Communication Research, 32, 726-761. doi:10.1177/0093650205281056

*Paletz, S. B. F., Chan, J., \& Schunn, C. D. (2016). Uncovering uncertainty through disagreement. Applied Cognitive Psychology, 30, 387-400. doi:10.1002/acp.3213

*Paletz, S. B. F., Kim, K. H., Schunn, C. D., Tollinger, I., \& Vera, A. (2013). Reuse and recycle: The development of adaptive expertise, routine expertise, and novelty in a large research team. Applied Cognitive Psychology, 27, 415-428. doi: $10.1002 /$ acp. 2928 
*Paletz, S. B. F., Schunn, C. D., \& Kim, K. H. (2013). The interplay of conflict and analogy in multidisciplinary teams. Cognition, 126, 1-19. doi:10.1016/j.cognition.2012.07.020

*Passos, P., Araújo, D., Davids, K., Gouveia, L., Serpa, S., Milho, J., \& Fonseca, S. (2009). Interpersonal pattern dynamics and adaptive behavior in multiagent neurobiological systems: Conceptual model and data. Journal of Motor Behavior, 41, 445-459. doi:10.3200/35-08-061

*Passos, P., Davids, K., Araújo, D., Paz, N., Minguéns, J., \& Mendes, J. (2011). Networks as a novel tool for studying team ball sports as complex social systems. Journal of Science and Medicine in Sport, 14, 170-176. doi:10.1016/j. jsams.2010.10.459

Pincus, S. M. (1991). Approximate entropy as a measure of system complexity. Proceedings of the National Academy of Sciences, 88, 2297-2301.

Pincus, S. M. (2006). Approximate entropy as a measure of irregularity for psychiatric serial metrics. Bipolar Disorders, 8,430-440. doi:10.1111/j.1399-5618.2006.00375.x

*Ponzi, D., Zilioli, S., Mehta, P. H., Maslov, A., \& Watson, N. V. (2016). Social network centrality and hormones: The interaction of testosterone and cortisol. Psychoneuroendocrinology, 68, 6-13. doi:10.1016/j.psyneuen.2016.02.014

*Quinlan, E., \& Robertson, S. (2013). The communicative power of nurse practitioners in multidisciplinary primary healthcare teams. Journal of the American Academy of Nurse Practitioners, 25, 91-102. doi:10.1111/j.1745-7599.2012.00768.x

*Quintane, E., Pattison, P. E., Robins, G. L., \& Mol, J. M. (2013). Short- and longterm stability in organizational networks: Temporal structures of project teams. Social Networks, 35, 528-540. doi:10.1016/j.socnet.2013.07.001

*Ramos-Villagrasa, P. J., Navarro, J., \& García-Izquierdo, A. L. (2012). Chaotic dynamics and team effectiveness: Evidence from professional basketball. European Journal of Work \& Organizational Psychology, 21, 778-802. doi:10.1 080/1359432X.2012.669525

*Reagans, R., Zuckerman, E., \& McEvily, B. (2004). How to make the team: Social networks vs. demography as criteria for designing effective teams. Administrative Science Quarterly, 49, 101-133. doi:10.2307/4131457

*Rebelo, T., Stamovlasis, D., Lourenço, P. R., Dimas, I., \& Pinheiro, M. (2016). A cusp catastrophe model for team learning, team potency and team culture. Nonlinear Dynamics, Psychology, and Life Sciences, 20, 537-563.

Rico, R. S., Alcover, C. M., \& Tabernero, C. (2011). Work team effectiveness, a review of research from the last decade (1999-2009). Psychology in Spain, 15, 57-79.

Rico, R. S., Gibson, C., Sánchez-Manzanares, M., \& Clark, M. (2014, October). On the interplay of implicit and explicit team coordination: Understanding team adaptation. Paper presented to the 2014 EAWOP Small Group Meeting Conference on Dynamics of Team Cognition and Team Adaptation, Lisbon, Portugal.

Rico, R. S., Sánchez-Manzanares, M., Gil, F., \& Gibson, C. (2008). Team implicit coordination processes: A team knowledge-based approach. Academy of Management Review, 33, 163-184. doi:10.5465/AMR.2008.27751276

Roe, R. A. (2008). Time in applied psychology: The study of "what happens" rather than "what is." European Psychologist, 13, 37-52. doi:10.1027/1016-9040.13.1.37 
Salas, E., Dickinson, T. L., Converse, S. A., \& Tannenbaum, S. I. (1992). Toward an understanding of team performance and training. In R. W. Swezey \& E. Salas (Eds.), Teams: Their training and performance (pp. 3-29). Westport, CT: Ablex Publishing.

*Sampaio, J. E., Lago, C., Gonçalves, B., Maçãs, V. M., \& Leite, N. (2014). Effects of pacing, status and unbalance in time motion variables, heart rate and tactical behaviour when playing 5-a-side football small-sided games. Journal of Science and Medicine in Sport, 17, 229-233. doi:10.1016/j.jsams.2013.04.005

*Sander, P. C., van Doorn, R. R. A., van der Pal, J., \& Zijlstra, F. R. H. (2015). Team adaptation to an unforeseen system failure: Limits of the potential aids of shared knowledge and standardized communication. European Journal of Work \& Organizational Psychology, 24, 796-811. doi:10.1080/1359432X.2015.1006199

*Sarker, S., Ahuja, M., Sarker, S., \& Kirkeby, S. (2011). The role of communication and trust in global virtual teams: A social network perspective. Journal of Management Information Systems, 28, 273-310. doi:10.2753/MIS07421222280109

*Sarker, S., Sarker, S., Kirkeby, S., \& Chakraborty, S. (2011). Path to "stardom" in globally distributed hybrid teams: An examination of a knowledge centered perspective using social network analysis. Decision Sciences, 42, 339-370.

*Sauer, N. C., \& Kauffeld, S. (2015). The ties of meeting leaders : A social network analysis. Psychology, 6, 415-434. doi:10.4236/psych.2015.64039

*Schulte, M., Cohen, N., \& Klein, K. (2012). The coevolution of network ties and perceptions of team psychological safety. Organization Science, 23, 564-581. doi:10.1287/orsc. 1100.0582

*Silva, P., Chung, D., Carvalho, T., Cardoso, T., Davids, K., Araújo, D., \& Garganta, J. (2016). Practice effects on intra-team synergies in football teams. Human Movement Science, 46, 39-51. doi:10.1016/j.humov.2015.11.017

*Silva, P., Duarte, R., Sampaio, J., Aguiar, P., Davids, K., Araújo, D., \& Garganta, J. (2014). Field dimension and skill level constrain team tactical behaviours in small-sided and conditioned games in football. Journal of Sports Sciences, 32, 1888-1896. doi:10.1080/02640414.2014.961950

*Sonnemans, J., van Dijk, F., \& van Winden, F. (2006). On the dynamics of social ties structures in groups. Journal of Economic Psychology, 27, 187-204. doi:10.1016/j.joep.2005.08.004

*Stevens, R. H., Galloway, T., Wang, P., Berka, C., Tan, V., Wohlgemuth, T., ... Buckles, R. (2013). Modeling the neurodynamic complexity of submarine navigation teams. Computational \& Mathematical Organization Theory. doi:10.1007/ s10588-012-9135-9

*Stevens, R. H., Gorman, J. C., Amazeen, P., Likens, A., \& Galloway, T. (2013). The organizational neurodynamics of teams. Nonlinear Dynamics, Psychology, and Life Sciences, 17, 67-86.

*Stevens, R. H., \& Galloway, T. L. (2014). Toward a quantitative description of the neurodynamic organizations of teams. Social Neuroscience, 9, 160-173. doi:10.1 080/17470919.2014.883324 
*Stojmenovic, M., \& Lindgaard, G. (2014). Social network analysis and communication in emergency response simulations. Journal of Organizational Computing and Electronic Commerce, 24, 236-256. doi:10.1080/10919392.2014.896729

*Strang, A. J., Funke, G. J., Russell, S. M., Dukes, A. W., \& Middendorf, M. S. (2014). Physio-behavioral coupling in a cooperative team task: Contributors and relations. Journal of Experimental Psychology: Human Perception and Performance, 40, 145-158. doi:10.1037/a0033125

*Suh, A., Shin, K., Ahuja, M., \& Kim, M. S. (2011). The influence of virtuality on social networks within and across work groups: A multilevel approach. Journal of Management Information Systems, 28, 351-386. doi:10.2753/MIS0742-1222280111

*Taramasco, C., Cointet, J. P., \& Roth, C. (2010). Academic team formation as evolving hypergraphs. Scientometrics, 85, 721-740. doi:10.1007/s11192-010-0226-4

Tranfield, D., Denyer, D., \& Smart, P. (2003). Towards a methodology for developing evidence-informed management knowledge by means of systematic review. British Journal of Management, 14, 207-222. doi:10.1111/1467-8551.00375

*Travassos, B., Araújo, D., Duarte, R., \& McGarry, T. (2012). Spatiotemporal coordination behaviors in futsal (indoor football) are guided by informational game constraints. Human Movement Science, 31, 932-945. doi:10.1016/j. humov.2011.10.004

*Travassos, B., Araújo, D., Vilar, L., \& Mcgarry, T. (2011). Interpersonal coordination and ball dynamics in futsal (indoor football). Human Movement Science, 30, 1245-1259. doi:10.1016/j.humov.2011.04.003

*Travassos, B., Gonçalves, B., Marcelino, R., Monteiro, R., \& Sampaio, J. (2014). How perceiving additional targets modifies teams' tactical behavior during football small-sided games. Human Movement Science, 38, 241-250. doi:10.1016/j. humov.2014.10.005

Urien, B., Rico, R., Demerouti, E., \& Bakker, A. (2017, May). Team job demandsresources ( $t J D-R$ ) theory: Team level formulation and cross-level relationships. Paper presented at the 18th EAWOP conference, Dublin, Ireland.

*Vidal, R., \& Roberts, K. H. (2014). Teams: The triad effect. Journal of Contingencies and Crisis Management, 22, 18-28.

*Vilar, L., Araújo, D., Davids, K., \& Travassos, B. (2012). Constraints on competitive performance of attacker-defender dyads in team sports. Journal of Sports Sciences, 30, 459-469. doi:10.1080/02640414.2011.627942

*Walker, G. H., Stanton, N. A., Salmon, P. M., Jenkins, D. P., Monnan, S., \& Handy, S. (2012). Communications and cohesion: A comparison between two command and control paradigms. Theoretical Issues in Ergonomics Science, 13, 508-527. doi:10.1080/1463922X.2010.544340

*Warner, S., Bowers, M. T., Dixon, M. A., Bowers Matthew, T., \& Dixon Marlene, A. (2012). Team dynamics: A social network perspective. Journal of Sport Management, 26, 53-66.

*Wehbe, F., Al Hattab, M., \& Hamzeh, F. (2016). Exploring associations between resilience and construction safety performance in safety networks. Safety Science, 82, 338-351. doi:10.1016/j.ssci.2015.10.006 
Whetten, D. A. (1989). What constitutes a theoretical contribution? Academy of Management Review, 14, 490-495.

*Wise, S. (2014). Can a team have too much cohesion? The dark side to network density. European Management Journal, 32, 703-711. doi:10.1016/j. emj.2013.12.005

*Yang, H.-L., \& Tang, J.-H. (2004). Team structure and team performance in IS development: A social network perspective. Information \& Management, 41, 335-349. doi:10.1016/S0378-7206(03)00078-8

Zaheer, S., Albert, S., \& Zaheer, A. (1999). Time scales and organizational theory. Academy of Management Review, 2, 4725-4741.

Zeeman, E. C. (1976). The umbilic bracelet and the double-cusp catastrophe. In P. Hilton (Ed.), Structural stability, the theory of catastrophes, and applications in the sciences (pp. 328-366). Berlin, Germany: Springer.

*Ziegler, A., Heckel, A., \& Ziegler, A. (2013). Mathematical foundations of and empirical investigations into the dynamic of top positions: Stabilization effect, reversed Matthew effect, and Heraclitus effect. Psychological Test and Assessment Modeling, 55, 401-414.

*Zurloni, V., Cavalera, C., Diana, B., Elia, M., \& Jonsson, G. (2014). Detecting regularities in soccer dynamics: A T-pattern approach. Revista de Psicologia del Deporte, 23, 157-164.

\section{Author Biographies}

Pedro J. Ramos-Villagrasa, $\mathrm{PhD}$, is an assistant professor at the University of Zaragoza, Spain. His current research activity is related with individual and team performance, personnel selection, and the application of complex adaptive systems to these topics.

Pedro Marques-Quinteiro, PhD, is a postdoctoral fellow at William James Center for Research, ISPA - Instituto Universitário, Portugal. His current research regards leadership and teams as complex adaptive systems, and performance in extreme work environments.

José Navarro, $\mathrm{PhD}$, is an associate professor at the University of Barcelona, Spain. His research activity is about work motivation as a dynamic process that evolves chaotically over time, and team processes and team tasks that influence critically on team effectiveness.

Ramón Rico, PhD, is an associate professor at the University of Western Australia, Perth, Australia. His current research interests include shared cognition and team adaptation, team diversity, task design characteristics, multiteam systems, and team process and effectiveness. 